This item was submitted to Loughborough's Research Repository by the author.

Items in Figshare are protected by copyright, with all rights reserved, unless otherwise indicated.

\title{
Photodegradation and ecotoxicology of acyclovir in water under UV254 and UV254/H2O2 processes
}

\section{PLEASE CITE THE PUBLISHED VERSION}

http://dx.doi.org/10.1016/j.watres.2017.06.020

\section{PUBLISHER}

(C) Elsevier

\section{VERSION}

AM (Accepted Manuscript)

\section{PUBLISHER STATEMENT}

This work is made available according to the conditions of the Creative Commons Attribution-NonCommercialNoDerivatives 4.0 International (CC BY-NC-ND 4.0) licence. Full details of this licence are available at: https://creativecommons.org/licenses/by-nc-nd/4.0/

\section{LICENCE}

CC BY-NC-ND 4.0

\section{REPOSITORY RECORD}

Russo, Danilo, A. Siciliano, M. Guida, Emilia Galdiero, Angela Amoresano, Roberto Andreozzi, Nuno M. Reis, Gianluca Li Puma, and Raffaele Marotta. 2017. "Photodegradation and Ecotoxicology of Acyclovir in Water Under UV254 and UV254/H2O2 Processes". figshare. https://hdl.handle.net/2134/25884. 
Research

Manuscript Number: WR38815R1

Title: Photodegradation and ecotoxicology of acyclovir in water under UV254 and UV254/H2O2 processes

Article Type: Research Paper

Keywords: UVC, hydrogen peroxide photolysis, microreactor, ecotoxicity, water reuse, acyclovir removal.

Corresponding Author: Professor Raffaele Marotta, Ph.D

Corresponding Author's Institution: University

First Author: Raffaele Marotta, Ph.D

Order of Authors: Raffaele Marotta, Ph.D; Danilo Russo; Antonietta Siciliano; Marco Guida; Emilia Galdiero; Angela Amoresano; Roberto Andreozzi; Nuno M Reis; Gianluca Li Puma

Abstract: The photochemical and ecotoxicological fate of acyclovir (ACY) through UV254 direct photolysis and in the presence of hydroxyl radicals (UV254/H2O2 process) were investigated in a microcapillary film (MCF) array photoreactor, which provided ultrarapid and accurate photochemical reaction kinetics. The UVC phototransformation of ACY was found to be unaffected by $\mathrm{pH}$ in the range from 4.5 to 8.0 and resembled an apparent autocatalytic reaction. The proposed mechanism included the formation of a photochemical intermediate ( $\square \mathrm{ACY}=(1.62 \pm 0.07) \square 10-3 \mathrm{~mol} \square \mathrm{ein}-1)$ that further reacted with ACY to form by-products $\left(\mathrm{k}^{\prime}=(5.64 \pm 0.03) \square 10-3 \mathrm{M}-\right.$ $1 \square \mathrm{s}-1)$. The photolysis of ACY in the presence of hydrogen peroxide accelerated the removal of ACY as a result of formation of hydroxyl radicals. The kinetic constant for the reaction of OH radicals with ACY $(\mathrm{kOH} / \mathrm{ACY})$ determined with the kinetic modeling method was (1.23 \pm $0.07) \square 109 \mathrm{M}-1 \square \mathrm{s}-1$ and with the competition kinetics method was (2.30 \pm $0.11) \square 109 \mathrm{M}-1{ }^{*} \mathrm{~S}-1$ with competition kinetics. The acute and chronic effects of the treated aqueous mixtures on different living organisms (Vibrio fischeri, Raphidocelis subcapitata, D. magna) revealed significantly lower toxicity for the samples treated with UV254/H202 in comparison to those collected during UV254 treatment. This result suggests that the addition of moderate quantity of hydrogen peroxide (30$150 \mathrm{mg} \square \mathrm{L}-1)$ might be a useful strategy to reduce the ecotoxicity of UV254 based sanitary engineered systems for water reclamation. 
Dear Editor, please find enclosed a copy of the paper "Photodegradation and ecotoxicology of acyclovir in water under $U V_{254}$ and $U V_{254} / H_{2} O_{2}$ processes" by Danilo Russo, Antonietta Siciliano, Marco Guida, Emilia Galdiero, Angela Amoresano, Roberto Andreozzi, Nuno M. Reis, Gianluca Li Puma and Raffaele Marotta, which has been revised according to the Referees' suggestions (all the corrections and new insertions have been printed in red bold typefaces).

We thank the Reviewers for the valuable suggestions that helped us to ameliorate the text. Thank you again for your assistance and cooperation.

Napoli, 3/6/2017

Yours sincerely

The Authors 
Reviewer \#1: The study targets at evaluating the UV and $\mathrm{UV} / \mathrm{H}_{2} \mathrm{O}_{2}$ treatment processes of the antiviral drug acyclovir. A microcapillary film array photoreactor was used to perform part of the experiments to reduce total volumes and time. At the same time 3 well-known bioassays were used to assess the effects of treated acyclovir solutions.

The manuscript is well written. The manuscript should be improved as follows.

Criticism. It is not clear how UV is a better treatment process than chlorination to overcome antibiotic resistant bacteria. The strengths and restrictions of the proposed treatment process should be clearly presented to better appreciate the study's findings.

Response: We thank the reviewer for the comment. We added some statements in the introduction to clarify this aspect

Criticism. A thorough literature review of research related to acyclovir, with the current state of the art as well as gaps-of-knowledge is currently missing from the introduction. Many studies have been done using acyclovir and $\mathrm{UV}_{254}$ treatment.

Response: At the best of our knowledge, as stated in the introduction, no investigations have been reported on the photochemical transformation of $A C Y$ under $U V_{254}$ and $U V_{254} / H_{2} \mathrm{O}_{2}$ treatments and on the ecotoxicological assessments on highly diluted treated solutions containing ACY. On the contrary, photodegradation pathways of ACY under artificial and natural solar light irradiation have been recently investigated (Zhou et al., Photolysis of three antiviral drugs acyclovir, zidovudine and lamivudine in surface freshwater and seawater. Chemosphere 138 (2015) 792-797; Prasse et al., Co-occurrence of photochemical and microbiological transformation processes in open-water unit process wetlands. Environmental Science \& Technology 49 (2015) 14136-14145).

Criticism. The rationale for using the specific bioassays, except their wide use and acceptance should be justified.

Response: The rationale for using these bioassays is the key information that need to be collected to determine the efficiency of the system investigated. In particular, in order to identify adverse human health and to take into account the ecotoxicity of the treated samples, we decided to use not only bacteria and microcrustacean but also algae and chronic test with Daphnia magna. These data are important because the continuous release of pharmaceuticals in the aquatic environment also at low concentrations and the importance of sublethal effects in the biota should be considered. 
Criticism. The analytical procedure should be described with greater detail. In some assays more toxic byproducts were observed. An attempt should be made to identify the toxic byproducts in order to increase the study's outcomes.

Response: As reported in several sections of the manuscript (abstract, introduction and conclusions), the present paper is a first investigation on the $\mathrm{UV}_{254} / \mathrm{H}_{2} \mathrm{O}_{2}$ photodegradation kinetics of ACY in distilled water and on the ecotoxicity of highly diluted treated samples. The analytical analysis of the phototransformation products, which differ among them depending to presence or absence of hydrogen peroxide and the UV-dose adopted, is very complex and requires (i) an accurate investigation about the fragmentation of acyclovir and the intermediates formed during $U V_{254}$ and $U V_{254} / H_{2} O_{2}$ processes using different diagnostic techniques (HPLC-MS/MS, GC-MS and NMR); (ii) a separation of the main photoproducts in order to check their ecotoxicity. The results collected from a large experimental campaign, which requires several months of experimental work, would be reasonably discussed in another extended dedicated analytical paper. However, a very preliminary analysis on sample submitted to $\mathrm{UV}_{254}$ and $\mathrm{UV}_{254} / \mathrm{H}_{2} \mathrm{O}_{2}$ processes indicated, as main photo-transformation by-products the presence of hydroxylated ACY based intermediates in the $U V_{254}$ treatment process, and hydroxylated imidazole based compounds or species formed by the fragmentation of the pyrimidine ring in the $\mathrm{UV}_{254} / \mathrm{H}_{2} \mathrm{O}_{2}$ treatment process. The results have been inserted in the manuscript in order to support the different trends of ecotoxicity observed on the samples submitted to two photolytic processes.

It is obvious that major efforts will be necessary to better characterize the mixtures treated at different $U V_{254}$ doses.

Criticism. It is not clear how the results from the microcapillary reactor and the photoreactor are comparable. The advantages of the microcapillary reactor should be enhanced so that the reader can understand why both type of experiments were needed.

Response: A key benefit of the microcapillary flow photoreactor over the batch annular photoreactor is the possibility to carry out the process using very small quantities of reagents in a highly controlled environment (the statement has been introduced in the revised text). Consequently, as stated in the original version of the manuscript, the adoption of microphotoreactor technology is particularly appropriate for investigations on such highly priced or scarcely available commercial substances, including illicit drugs or selected pharmaceuticals. On the contrary, as discussed in section 3.2, a cylindrical batch photoreactor $(0.480 \mathrm{~L})$ was used to provide sufficient sample volumes to carry out the ecotoxicity tests and the chemical intermediates analysis at varying treatment times. 
Criticism. The experiments should be also performed using real or simulated environmental matrices in order to increase their environmental relevance.

Response: The kinetics of photodegradation of an organic substrate in real matrices (urban wastewater effluent, surface water, etc) are highly influenced by their composition (i.e. nature and concentration of the inorganic and organic species, $p H$, etc..). These variables change depending on the nature of the influent and the type of the physico-chemical treatment adopted. In the present paper we investigated the kinetics of acyclovir under $U V_{254}$ irradiation in distilled water.

For toxicity tests, neither real nor other simulated environmental matrices were used, considering the large number of chemicals in an effluent and the possibility of interactions (e.g. synergy or additivity) between them and the byproducts of treated solutions.

Moreover, as stated in the conclusions of the manuscript (original version), further efforts are required to evaluate possible cumulative effects of the different species occurring in STP effluents. For this reason, these effects cannot be evaluated and consequently generalized using a single real matrix. However, some additional runs performed in synthetic wastewater were carried out and the results inserted in the text (figures $2 l-m$ ) in order to validate the kinetic model proposed.

Criticism. It is not clear what was the initial concentration of acyclovir when the microcapillary experiments were performed.

Response: Required information was added in section 3.1. of the manuscript.

Criticism. No explanation on the statistical analysis of results are presented. For instance the LOD/LOQ, the deviation, the QC/QA are not described in detail.

Response: The required control data were reported in the text and referred to the pertinent paragraphs.

Criticism. The discussion section could be augmented in context and length to increment the study's findings.

Response: Following the reviewer's suggestion, we added additional information about the mineralization degree, the photodegradation of $A C Y$ in synthetic effluents and the proposed structures of main by-products.

Criticism. The methods for evaluating the biochemical endpoints could be described in greater detail. Apart from this, reference on the method used should be given. 
Response: Additional information have been added as suggested by the reviewer.

Reviewer \#2: The manuscript WR38815 presents an interesting research work related to the photodegradation and ecotoxicology of acyclovir in water under $\mathrm{UV}_{254}$ and $\mathrm{UV}_{254 / \mathrm{H} 2 \mathrm{O} 2}$ processes. The information gathered in this work is relevant for the scientific community, therefore, the manuscript can be accepted for WR after minor revisions.

Criticism. The standard errors of the kinetic constants must have only one significant number (example: $1.62+-0.07 ; 5.64+-0.03 ; 2.3+-0.1 ; 1.23+-0.07$ ).

Response: Done

Criticism. Please define all the variables used in the kinetic models and include units.

Response: The photon fluxes per unit volume emitted by the UV lamp $\left(P_{o}\right)$ and the MCF average optical path length $\left(l_{M C F}\right)$ have been defined in section 3.1 of the original version of the manuscript (lines 132-136). The term $\varepsilon_{254}^{A C Y}$, as reported in the manuscript (original version, lines 253-254), is the molar absorption coefficient at $254 \mathrm{~nm}$ for ACY at $\mathrm{pH} 4.5,6.0$ and $8.0\left(1.21 \cdot 10^{-2} \mathrm{M}^{-1} \mathrm{~cm}^{-1}\right)$, whereas $\phi_{A C Y}$ and $k$ ' are the quantum yield of photolysis of ACY at $254 \mathrm{~nm}$ (lines 248-249) and the kinetic constant for reaction in scheme 1 (lines 249). The respective values and units are reported at lines 260-261 (original version).

Additional information has been added in the revised version of the paper (caption for table 2).

Criticism. Please include the kinetics of acyclovir degradation in a real matrix (urban wastewater after secondary treatment).

Response: We thank the reviewer for the suggestion, however, on the basis of our experience, the kinetics of the direct and indirect photodegradation of an organic substrate in real matrices (urban wastewater effluent, surface water, etc) are strongly affected by the nature and the concentration of the inorganic and organic substances contained. These variables change depending on the nature of the influent and the type of the physico-chemical treatment adopted. The present paper is a first preliminary investigation on the kinetics of acyclovir under $U V_{254}$ irradiation in distilled water. Moreover, as stated in the conclusions of the manuscript (original version), further efforts are required to evaluate possible cumulative effects of the different species occurring in STP effluents. For these reasons, these effects cannot be evaluated and consequently generalized using a single real matrix. 
Criticism. Please include some information about the mineralization of acyclovir and degradation by-products.

Response: The analytical analysis of the phototransformation products, which differ among them depending to presence or absence of hydrogen peroxide and the UV-dose adopted, is very complex and it requires (i) an accurate investigation about the fragmentation of acyclovir and the intermediates formed during $U V_{254}$ and $U V_{254} / H_{2} O_{2}$ processes using different diagnostic techniques (HPLC-MS/MS, GC-MS and NMR); (ii) a separation of the main photoproducts in order to check their ecotoxicity. The results collected from a large experimental campaign, which requires several months of experimental work, would be reasonably discussed in another extended dedicated analytical paper. However, a very preliminary analysis on treated samples (reported in the revised version of the manuscript) indicated, as main photo-transformation by-products, the presence of hydroxylated $A C Y$ based intermediates in the $U V_{254}$ treatment process, and hydroxylated imidazole based compounds or species formed by the fragmentation of the pyrimidine ring in the $\mathrm{UV}_{254} / \mathrm{H}_{2} \mathrm{O}_{2}$ treatment process. Moreover, TOC removal degrees were inserted in table 3 and in the revised text. 
- Photolysis and $\mathrm{UV} / \mathrm{H}_{2} \mathrm{O}_{2}$ degradation of acyclovir were studied in a microphotoreactor

- $\mathrm{UV}_{254}$ photolysis quantum yield of acyclovir was estimated $\left(1.62 \cdot 10^{-3} \mathrm{~mol}^{\left.-\mathrm{ein}^{-1}\right)}\right.$

- Kinetic constant of hydroxyl radical attack to acyclovir was evaluated

- $\mathrm{H}_{2} \mathrm{O}_{2}$ assisted photo-oxidation process reduces the ecotoxicity of acyclovir 

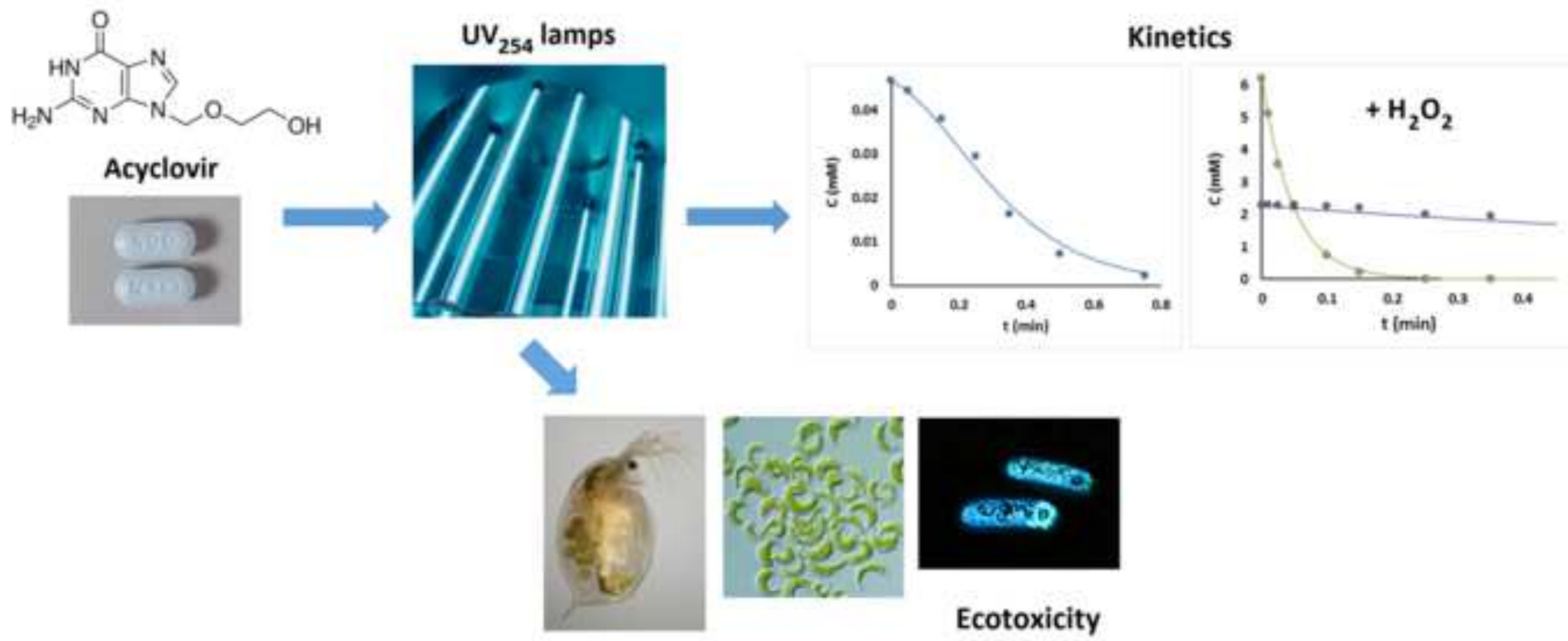

\section{Ecotoxicity}


1 Photodegradation and ecotoxicology of acyclovir in water under UV $\mathbf{V}_{254}$ and

$2 \quad \mathrm{UV}_{254} / \mathrm{H}_{2} \mathrm{O}_{2}$ processes

3

4 Danilo Russo ${ }^{\mathrm{a}}$, Antonietta Siciliano ${ }^{\mathrm{b}}$, Marco Guida ${ }^{\mathrm{b}}$, Emilia Galdiero ${ }^{\mathrm{b}}$, Angela Amoresano ${ }^{\mathrm{c}}$,

5 Roberto Andreozzi ${ }^{\mathrm{a}}$, Nuno M. Reis ${ }^{\mathrm{d}, \mathrm{e}}$, Gianluca Li Puma ${ }^{\mathrm{e}, \dot{\hbar}}$ and Raffaele Marotta ${ }^{\mathrm{a}, \dagger}$

6

8 Napoli Federico II, p.le V. Tecchio 80, Napoli, Italy.

9

${ }^{a}$ Dipartimento di Ingegneria Chimica, dei Materiali e della Produzione Industriale, Università di

${ }^{\mathrm{b}}$ Dipartimento di Biologia, Università di Napoli Federico II, Complesso Universitario Monte Sant'Angelo, via Cinthia 4, Napoli, Italy.

${ }^{c}$ Dipartimento di Scienze Chimiche, Università di Napoli Federico II, Complesso Universitario Monte Sant'Angelo, via Cinthia 4, Napoli, Italy.

${ }^{\mathrm{d}}$ Department of Chemical Engineering, University of Bath, Claverton Down, Bath BA2 7AY, UK.

${ }^{\mathrm{e}}$ Environmental Nanocatalysis \& Photoreaction Engineering Department of Chemical Engineering, Loughborough University, Loughborough LE11 3TU, UK.

$\dagger$ Corresponding author: Tel.: +39(0)817682968, fax: +39815936936. E-mail address: rmarotta@unina.it (R. Marotta).

* Corresponding author: Tel.: +44(0)1509222510, fax: +44(0)1509223923. E-mail address: G.Lipuma@lboro.ac.uk (G. Li Puma).

\section{Abstract}

The photochemical and ecotoxicological fate of acyclovir (ACY) through $\mathrm{UV}_{254}$ direct photolysis and in the presence of hydroxyl radicals $\left(\mathrm{UV}_{254} / \mathrm{H}_{2} \mathrm{O}_{2}\right.$ process) were investigated in a microcapillary film (MCF) array photoreactor, which provided ultrarapid and accurate photochemical reaction 
kinetics. The UVC phototransformation of $\mathrm{ACY}$ was found to be unaffected by $\mathrm{pH}$ in the range from 4.5 to 8.0 and resembled an apparent autocatalytic reaction. The proposed mechanism included the formation of a photochemical intermediate $\left(\phi_{A C Y}=(1.62 \pm \mathbf{0 . 0 7}) \cdot 10^{-3} \mathrm{~mol}^{-e^{-1}}\right)^{-1}$ that further reacted with ACY to form by-products $\left(k^{\prime}=(5.64 \pm \mathbf{0 . 0 3}) \cdot 10^{-3} \mathrm{M}^{-1} \cdot \mathrm{s}^{-1}\right)$. The photolysis of $\mathrm{ACY}$ in the presence of hydrogen peroxide accelerated the removal of ACY as a result of formation of hydroxyl radicals. The kinetic constant for the reaction of $\mathrm{OH}$ radicals with ACY $\left(k_{O H / A C Y}\right)$ determined with the kinetic modeling method was $(1.23 \pm 0.07) \cdot 10^{9} \mathrm{M}^{-1} \cdot \mathrm{s}^{-1}$ and with the competition kinetics method was $(2.30 \pm \mathbf{0 . 1 1}) \cdot 10^{9} \mathrm{M}^{-1} \cdot \mathrm{s}^{-1}$ with competition kinetics. The acute and chronic effects of the treated aqueous mixtures on different living organisms (Vibrio fischeri, Raphidocelis subcapitata, D. magna) revealed significantly lower toxicity for the samples treated with $\mathrm{UV}_{254} / \mathrm{H}_{2} \mathrm{O}_{2}$ in comparison to those collected during $\mathrm{UV}_{254}$ treatment. This result suggests that the addition of moderate quantity of hydrogen peroxide $\left(30-150 \mathrm{mg} \cdot \mathrm{L}^{-1}\right)$ might be a useful strategy to reduce the ecotoxicity of $\mathrm{UV}_{254}$ based sanitary engineered systems for water reclamation.

Keywords: UVC, hydrogen peroxide photolysis, microreactor, ecotoxicity, water reuse, acyclovir removal.

\section{Introduction}

Water reclamation and water reuse is becoming increasingly common in industrialized countries with high water demands and in water stressed regions characterized by considerable scarcity of freshwater (Hoekstra, 2014). The most common treatment method for water reuse is chlorination at typical dosages ranging from 5 to $20 \mathrm{mg} / \mathrm{L}$ with a maximum of two hours of contact time (Asano, 1998). However, concerns related to (i) the adverse impacts of chlorine on irrigated crops, (ii) the high ecotoxicity of chlorinated by-products (DBPs) formed during the chlorination stage (Richardson et al., 2007) and (iii) the survival of antibiotics resistant bacteria during chlorination 
51 (Khan et al., 2016) with a possible selection of some antibiotic resistance genes in the wastewater microbial community (Huang et al., 2011) should drive the transition from chlorine disinfection to other more ecofriendly suitable methods. UV radiation treatment (especially UVC, $\lambda<280 \mathrm{~nm}$ ) produces a high sterilization efficiency (Montemayor et al., 2008) and could represent a viable alternative to chlorination for the disinfection and reuse of effluents from wastewater treatment plant (WWTP) for irrigation (i.e., after membrane filtration and/or reverse osmosis) or for aquifer recharge. Numerous wastewater sites have adopted UVC treatment for effluents disinfection. For example, Florida and California have favored wastewater reuse and adopted specific regulations on reclamation technologies through UV disinfection processes. UVC doses (fluence) ranging from $50 \mathrm{~mJ} \cdot \mathrm{cm}^{-2}$ to $150 \mathrm{~mJ} \cdot \mathrm{cm}^{-2}$ have been suggested to efficiently inactivate pathogens accounting for the variability in the effluent composition (NWRI, 2012), although German and Austrian regulations (DVGW,1997; ONorm, 2001) suggest the use of $40 \mathrm{~mJ} \cdot \mathrm{cm}^{-2}$ UVC fluence to eliminate a large variety of bacteria and viruses (Conner-Kerr et al., 1998). Even though UV disinfection has been reported highly effective in the reduction of antibiotic resistance bacteria (ARB), particularly in comparison to chlorination (Shi et al., 2013; Hijnen et al., 2006), other investigations have demonstrated that UV disinfection may not contribute to the significant reduction of selected ARB, such as tetracycline-and sulfonamide-resistant bacteria (Munir et al., 2011; Meckes, 1982) thus indicating a plausible selectivity of UV on ARB (Guo et al., 2013).

Moreover, numerous studies have suggested that under the recommended UVC doses several biorefractory xenobiotics, particularly pharmaceuticals and personal care products generally occurring in municipal discharges and partially removed in WWTPs, may undergo photochemical transformations induced by UVC irradiation (Canonica et al., 2008; Nick et al., 1992; Pereira et al, 2007; Kim et al., 2009; Ma et al., 2016; Kovacic et al., 2016; Liu et al., 2016; Marotta et al., 2013) which may generate by-products with high ecotoxicity (Rozas et al., 2016; Yuan et al., 2011). For these reasons, the use of hydrogen peroxide during UVC disinfection $\left(\mathbf{U V}_{\mathbf{2 5}} / \mathbf{H}_{2} \mathbf{O}_{2}\right)$ which 
produces highly reactive radical species, has been proposed as a viable treatment for effective removal of micropollutant and $\mathrm{ARB}$ and, in consequence, for the reduction of the ecotoxicity risk (García-Galan et al., 2016; Melo da Silva et al., 2016).

Among the emerging Pharmaceuticals and Personal Care Products detected in WWTP effluents, antiviral drugs play a leading role (Richardson, 2012; Jain et al., 2013) due to their scarce biodegradability (Funke et al., 2016) and increased usage during the last decade, particularly for the treatment of viral diseases and for the prevention of pandemic outbreaks (Hill et al., 2014). Moreover, antiviral drugs have been considered as some of the most hazardous therapeutic substances exerting high toxicity towards biota, such as crustaceans, fish and algae (Sanderson et al., 2004). The presence of antiviral drugs in the environment raises considerable concern regarding their potential effect on the ecosystem, with the potential of developing antiviral drug resistance, in analogy to the development of antibiotic resistant bacteria (Singer et al., 2007; Gillman et al., 2015).

Acyclovir (ACY) is one of the oldest and most widely used antiviral drug for treating two common viral infections (chickenpox-zoster and herpes simplex) and it is also prescribed to patients with weakened immune systems in order to control viral infections (i.e., viral conjunctivitis) (BryanMarrugo et al., 2015). ACY has been recently detected in different WWTP effluents as well as in surface water at level of few nanograms per liter up to over one micrograms per liter (Table 1).

The photodegradation pathways of ACY under artificial and natural solar light irradiation have been recently investigated (Zhou et al., 2015; Prasse et al., 2015). However, there is a lack of investigations on the photochemical transformation of ACY under $\mathrm{UV}_{254}$ and $\mathrm{UV}_{254} / \mathrm{H}_{2} \mathrm{O}_{2}$ treatments and on the simultaneous ecotoxicological assessments of highly diluted treated solutions containing ACY.

More information is needed to determine the effectiveness of $\mathrm{UV}_{254}$ assisted processes on the removal of ACY from aqueous solutions and the impact that these processes may have on the structure of aquatic communities and on the ecosystem dynamics. 
103 The use of microcapillary flow photoreactors has recently been proposed to intensify the 104 treatment of substances that are either highly priced, scarcely commercially available or 105 controlled substances such as illicit drugs or selected pharmaceuticals (Reis and Li Puma, 2015; 106 Russo et al., 2016). In contrast to conventional laboratory photochemical systems which 107 require relatively larger volume of liquid, photochemical treatments in microphotoreactors are 108 carried out in a highly controlled environment with minimal sample volumes (of the order of few $109 \mathrm{~mL}$ ), the sufficient amount to generate samples for subsequent analysis. Furthermore, 110 photochemical transformations in microphotoreactors are executed at extremely short residence 111 times (of the order of seconds) in comparison to conventional laboratory photoreactors, resulting in 112 an efficient use of time and resources.

113 Under this background, in this study we investigated the degradation kinetics of ACY in 114 distilled water under $\mathrm{UV}_{254}$ and $\mathrm{UV}_{254} / \mathrm{H}_{2} \mathrm{O}_{2}$ irradiation by means of a microcapillary film (MCF) 115 array photoreactor and we evaluated the acute and chronic ecotoxicity of highly diluted treated 116 samples using a range of selected organisms, to provide important information regarding the 117 photolysis of ACY in $\mathrm{UV}_{254}$ based sanitary engineered systems for water reclamation. The toxicity 118 was assessed considering a battery of toxicity tests (Aliivibrio fischeri, Raphidocelis 119 subcapitata, Daphnia magna) and endpoints (bioluminescence, growth inhibition, 120 immobilization, survival, reproduction and biomarker) including three trophic and 121 phylogenetic levels (Lofrano et al., 2016).

122 The battery of toxicity tests proposed were sensitive indicators of toxic pollutants, and also 123 determined the great diversity of potential stress-receptor that could result from 124 pharmaceuticals and their byproducts entering the environment (FDA, 1998). 
Hydrogen peroxide ( $30 \% \mathrm{v} / \mathrm{v})$, ACY (pharmaceutical secondary standard), methanol $(\geq 99.9 \% \mathrm{v} / \mathrm{v})$, formic acid ( $>99 \% \mathrm{w} / \mathrm{w})$, benzoic acid ( $\geq 99.5 \% \mathrm{w} / \mathrm{w})$, orthophosphoric acid $\left(85 \% \mathrm{w} / \mathrm{w}\right.$ in $\left.\mathrm{H}_{2} \mathrm{O}\right)$, sodium hydroxide (>98\% w/w), perchloric acid (70\% v/v), catalase from Micrococcus lysodeikticus and reagents for ecotoxicity tests were purchased from Sigma-Aldrich. An aqueous mixture of peptone (32 ppm), meat extract (22 ppm), urea (6 ppm), $\mathrm{K}_{2} \mathrm{HPO}_{4}(28 \mathrm{ppm}), \mathrm{CaCl}_{2} \cdot \mathrm{H}_{2} \mathrm{O}(4$ ppm), $\mathrm{NaCl}(7 \mathrm{ppm})$ and $\mathrm{Mg}_{2} \mathrm{SO}_{4}(0.6 \mathrm{ppm})$ was used for the preparation of a synthetic wastewater according to the OECD Guidelines (Organisation for Economic Cooperation and development, 1999). The substances were purchased from Sigma-Aldrich and used as received. Milli-Q water was used as solvent in analytical determinations and experiments.

\subsection{Analytical methods}

The concentration of hydrogen peroxide, ACY, and benzoic acid was measured by HPLC (1100 Agilent) equipped with a Gemini 5u C6-Phenyl 110 (Phenomenex) reverse phase column and a diode array detector. The mobile phase was a mixture of 93\% aqueous orthophosphoric acid (10 $\mathrm{mM}$ ) and $7 \%$ methanol flowing at $8.0 \cdot 10^{-4} \mathrm{~L} \cdot \mathrm{min}^{-1}$. The $\mathrm{pH}$ of the aqueous solutions was adjusted with $\mathrm{NaOH}$ or $\mathrm{HClO}_{4}$ and measured with an Accumet Basic AB-10 pH-meter. The molar absorption coefficient of ACY was estimated using a Perkin Elmer UV/VIS spectrometer (mod. Lambda 35). Total organic carbon (TOC) was monitored by a TOC analyzer (Shimadzu 5000 A). MS analysis was performed by direct injection on Agilent 6230 TOF LC/MS coupled with Agilent HPLC system (1260 Series). The mobile phase was a mixture of methanol $(10 \% \mathrm{v} / \mathrm{v})$ and formic acid $(0.1 \% \mathrm{v} / \mathrm{v})$ aqueous solution at flow rate of $0.4 \mathrm{~mL} \cdot \mathrm{min}^{-1}$ and the injection volume of samples was $20 \mu \mathrm{L}$. The MS source was an electrospray ionization (ESI) interface in the positive ion mode with capillary voltage of $3500 \mathrm{~V}$, gas temperature at $325{ }^{\circ} \mathrm{C}$, dry gas $\left(\mathrm{N}_{2}\right)$ flow at $8 \mathrm{~L} \cdot \mathrm{min}^{-1}$ and the nebulizer at $35 \mathrm{psi}$. The MS spectra were acquired in a mass range of $100-3000 \mathrm{~m} / \mathrm{z}$ with a rate of 1 spectrum/s, time of $1000 \mathrm{~ms} / \mathrm{spectrum}$ and transient/spectrum of 9905 . 


\section{3. Experimental apparatus and procedures}

156

157

158

159

160

161

162

163

164

165

166

167

168

169

170

171

172

\subsection{MCF array photoreactor}

The degradation kinetics of ACY by $\mathrm{UV}_{254}$ and $\mathrm{UV}_{254} / \mathrm{H}_{2} \mathrm{O}_{2}$ were investigated in a MCF array photoreactor described elsewhere (Reis et al., 2015; Russo et al., 2016). Briefly, the photoreactor (Lamina Dielectrics Ltd) consisted of ten $\mathbf{U V}_{254}$ transparent microcapillaries of fluorinated polymer characterized by a mean hydraulic diameter of $195 \mu \mathrm{m}$. The microcapillaries were coiled around a UV monochromatic (254 nm) lamp (Germicidal G8T5) in the region with uniform emission. Experiments were carried out at room temperature $\left(\sim 25^{\circ} \mathrm{C}\right)$ in continuous flow through the reactor at different space times, using capillaries of different length exposed to the UV lamp irradiation. The flow rate through the MCF was $6.0 \cdot 10^{-4} \mathrm{~L} \cdot \mathrm{min}^{-1}$. Aqueous samples were collected from the MCF outlet, and rapidly analyzed by HPLC. At the end of each experimental run, the $\mathrm{pH}$ of the solutions was unchanged. The initial concentration of ACY used in the experiments ranged between $2.05 \cdot 10^{-5} \mathrm{~mol} \cdot \mathrm{L}^{-1}$ and $4.67 \cdot 10^{-5} \mathrm{~mol} \cdot \mathrm{L}^{-1}$.

The lamp irradiance was varied by changing the nominal power from $4.5 \mathrm{~W}$ to $8.0 \mathrm{~W}$ using a variable power supply unit. The photon fluxes per unit volume emitted by the UV lamp $\left(P_{o}\right)$ for each power setting, estimated by $\mathrm{H}_{2} \mathrm{O}_{2}$ actinometry (Nicole et al, 1990; Goldstein et al., 2007), were

$1.92 \cdot 10^{-2}$ ein $\cdot(\mathrm{s} \cdot \mathrm{L})^{-1}$ (nominal power $8.0 \mathrm{~W}$ ) and $1.27 \cdot 10^{-2}$ ein $\cdot(\mathrm{s} \cdot \mathrm{L})^{-1}$ (nominal power $\left.4.5 \mathrm{~W}\right)$. The MCF average optical path length $\left(l_{M C F}\right)$ was $154 \mu \mathrm{m}$. All the runs were carried out in duplicate. The data collected were used to estimate the kinetic unknown parameters (quantum yield of direct photolysis at $254 \mathrm{~nm}$ of ACY and kinetic constant of hydroxyl radical attack to ACY).

\subsection{Cylindrical batch photoreactor}

A cylindrical batch photoreactor $\left(\mathrm{V}_{\mathrm{b}}=0.480 \mathrm{~L}\right)$, equipped with a low-pressure mercury monochromatic lamp (Helios Italquartz, HGL10T5L, 17W nominal power emitting at $254 \mathrm{~nm}$ ), was used to provide large sample volumes required for the ecotoxicity tests at varying treatment times 
180 (i.e., different $\mathrm{UV}_{254}$ fluence). The $\mathrm{UV}_{254}$ dose $\left(\mathrm{mJ} \cdot \mathrm{cm}^{-2}\right)$ was calculated as the average photon 181 fluence rate multiplied by the treatment time. The average photon fluence rate emitted by the UV 182 lamp at $254 \mathrm{~nm}$ was $4.7 \mathrm{~mW} \cdot \mathrm{cm}^{-2}$ (UVC DELTA OHM radiometer). The experimental device was 183 described elsewhere (Spasiano et al., 2016).

\subsection{Ecotoxicity assessment}

Reconstituted aqueous solution $(\mathrm{pH}=7.8 \pm 0.2$ ), was used as dilution water for cladoceran toxicity tests: $\mathrm{CaCl}_{2} \cdot 2 \mathrm{H}_{2} \mathrm{O}\left(290 \mathrm{mg} \cdot \mathrm{L}^{-1}\right), \mathrm{MgSO}_{4} \cdot 7 \mathrm{H}_{2} \mathrm{O}\left(120 \mathrm{mg} \cdot \mathrm{L}^{-1}\right), \mathrm{NaHCO}_{3}\left(65 \mathrm{mg} \cdot \mathrm{L}^{-1}\right), \mathrm{KCl}(6$ $\left.\mathrm{mg} \cdot \mathrm{L}^{-1}\right)$. Different salts were used for the preparation of algal test medium: $\mathrm{CaCl}_{2} \cdot 2 \mathrm{H}_{2} \mathrm{O}\left(18 \mathrm{mg} \cdot \mathrm{L}^{-}\right.$

$\left.{ }^{1}\right), \mathrm{MgSO}_{4} \cdot 7 \mathrm{H}_{2} \mathrm{O}\left(15 \mathrm{mg} \cdot \mathrm{L}^{1}\right), \mathrm{NH}_{4} \mathrm{Cl}\left(15 \mathrm{mg} \cdot \mathrm{L}^{-1}\right), \mathrm{MgCl}_{2} \cdot 6 \mathrm{H}_{2} \mathrm{O}\left(12 \mathrm{mg} \cdot \mathrm{L}^{-1}\right), \mathrm{KH}_{2} \mathrm{PO}_{4}\left(1.6 \mathrm{mg} \cdot \mathrm{L}^{-1}\right)$, $\mathrm{FeCl}_{3} \cdot 6 \mathrm{H}_{2} \mathrm{O}\left(0.08 \mathrm{mg} \cdot \mathrm{L}^{-1}\right), \mathrm{Na}_{2} \mathrm{EDTA}_{2} \cdot \mathrm{H}_{2} \mathrm{O}\left(0.1 \mathrm{mg} \cdot \mathrm{L}^{-1}\right), \mathrm{H}_{3} \mathrm{BO}_{3}\left(0.185 \mathrm{mg} \cdot \mathrm{L}^{-1}\right), \mathrm{MnCl}_{2} \cdot 4 \mathrm{H}_{2} \mathrm{O}$ $\left.\mathrm{mg} \cdot \mathrm{L}^{-1}\right), \mathrm{CuCl}_{2} \cdot 2 \mathrm{H}_{2} \mathrm{O}\left(1.0 \cdot 10^{-5} \mathrm{mg} \cdot \mathrm{L}^{-1}\right)$. Reconstitution solution, osmotic adjusting solution (OAS) and diluent $(\mathrm{NaCl} 2 \%)$ were the reagents used in Vibrio fischeri toxicity test (Strategic diagnostics Inc. SDI).

The enzymatic assays chosen to evaluate oxidative stress were ROS (reactive oxygen species) content using 2,7- dichlorodihydrofluorescein $\left(\mathrm{H}_{2}\right.$ DCFDA) and activities of SOD (superoxide dismutase), CAT (catalase) and GST (glutathione transferase) that were measured using respective assay kits according to the manufactorer's instruction's (Sigma Aldrich). All determinations were quantified spectrophotometrically.

V. fischeri, R. subcapitata and acute D. magna assays were conducted with an initial ACY concentration of $1.2 \mathrm{mg} \cdot \mathrm{L}^{-1}$ and on its related $\mathrm{UV}_{254}$ and $\mathrm{UV}_{254} / \mathrm{H}_{2} \mathrm{O}_{2}$ treated solutions. Chronic toxicity and oxidative stress tests on Daphnia magna were performed starting on untreated and treated solutions diluted by 100 fold, in order to assess any differences at sub lethal concentration 
differences of toxicity between the treated samples and controls was assessed by the analysis of variance (ANOVA) considering a significance threshold level always set at $5 \%$. For higher variance than 5\%, post-hoc tests were carried out with Dunnett's method and Tukey's test. Whenever possible, toxicity was expressed as median effective concentration $\left(\mathrm{EC}_{50}\right)$ with $95 \%$ confidence limit values. Otherwise, toxicity was expressed as percentage of effect (PE, \%).

\subsubsection{Organisms maintenance and monitoring}

Freeze-dried Vibrio fischeri (strain NRRL-B-11177) cells were reconstituted with reagent diluent at $4{ }^{\circ} \mathrm{C}$. Raphidocelis subcapitata were cultured in ISO medium (ISO, 2012) at $23 \pm 2{ }^{\circ} \mathrm{C}$ with continuous 4500 lux light and aeration (0.2 mm filtered air). Daphnia magna were cultured at $20 \pm$ $1{ }^{\circ} \mathrm{C}$, with a 16:8 light/dark photoperiod in ISO water (ISO, 2012).

Luminescence $V$. fischeri measurements were performed with Microtox ${ }^{\circledR}$ Model 500 Toxicity Analyzer from Microbics Corporation (AZUR Environmental) equipped with a 30 well incubated at $15 \pm 1{ }^{\circ} \mathrm{C}$ and with excitation source at $490 \mathrm{~nm}$ wavelength.

R. subcapitata density was determined by an indirect procedure using a spectrophotometer (Hach Lange DR5000) and cuvette $(5 \mathrm{~cm})$. D. magna viability, mobility and growth were observed with a stereomicroscope (LEICA EZ4-HD).

\subsubsection{Bacteria toxicity test}

The inhibitory effect of ACY samples on the light emission of V. fischeri (strain NRRL-B-11177) was evaluated with the 11348-3:2007 ISO method (ISO, 2007). Tests were carried out on an ACY concentration of $1.2 \mathrm{mg} \cdot \mathrm{L}^{-1}$ and on its related treated by-products solutions. OAS was added to each sample to ensure that the final $\mathrm{NaCl}$ concentration was above $2.0 \%$. The initial light output from each cuvette containing reconstituted freeze-dried $V$. fischeri was recorded. The test solutions were then added and after 30 minutes exposure, the final light output was measured. Positive control tests for $V$. fischeri were carried out with $\mathrm{C}_{6} \mathrm{H}_{4} \mathrm{Cl}_{2} \mathrm{O}\left(\mathrm{EC}_{50}=4.1 \pm 2.2 \mathrm{mg} \cdot \mathrm{L}^{-1}\right)$. 


\subsubsection{Algae toxicity test}

233 The R. subcapitata bioassay was conducted following the guidelines ISO 8692 (ISO, 2012). Three 234 replicates were included for each sample. The replicates were inoculated with $10^{4}$ algal cells $\cdot \mathrm{mL}^{-1}$ 235 and incubated for $72 \mathrm{~h}$ at $23 \pm 2{ }^{\circ} \mathrm{C}$ under continuous illumination (irradiance range of 120-60 $\left.236 \mu \mathrm{ein} \cdot \mathrm{m}^{-2} \cdot \mathrm{s}^{-1}\right)$. The algal biomass exposed to the samples was compared with the algal biomass in the 237 negative control. Positive control tests for $R$. subcapitata were carried out with $\mathrm{K}_{2} \mathrm{Cr}_{2} \mathrm{O}_{7}\left(\mathrm{EC}_{50}\right.$ $\left.238=1 \pm 0.2 \mathrm{mg} \cdot \mathrm{L}^{-1}\right)$.

\subsubsection{Crustaceans toxicity test}

Acute toxicity tests with D. magna were carried out according to ISO 6341 (ISO, 2013). Newborn daphnids ( $<24 \mathrm{~h}$ old) were exposed in four replicates for $24 \mathrm{~h}$ and $48 \mathrm{~h}$ at $20 \pm 1{ }^{\circ} \mathrm{C}$. Toxicity was expressed as percentage of immobilized organisms. Positive control tests for $D$. magna were carried out with $\mathrm{K}_{2} \mathrm{Cr}_{2} \mathrm{O}_{7}\left(48 \mathrm{~h}, \mathrm{EC}_{50}=0.6 \pm 0.1 \mathrm{mg} \cdot \mathrm{L}^{-1}\right)$.

The D. magna chronic bioassay was carried out according to the guideline OECD 211 (OECD, 2012). Ten $D$. magna neonates ( $<24 \mathrm{~h}$ hold) were used and individually placed for each treatment in beakers containing $50 \mathrm{ml}$ of the test solutions, renewed every two other days. Organisms exposed 248 for 21 days with ACY solutions were then fed one day with $R$. subcapitata $\left(10^{7}\right.$ cell $\left.\cdot \mathrm{mL}^{-1}\right)$. 249 Survival, reproduction and growth were observed daily, and newborns were discarded from 250 beakers.

251 The amount of ROS produced in D. magna was determined using 2,7-dichlorodihydrofluorescein 252 ( $\mathrm{H}_{2} \mathrm{DCFDA}$, Sigma Aldrich) using the method previously reported (Galdiero et al., 2016). After 48 $253 \mathrm{~h}$ of exposure, each exposed and not exposed living daphnids were rinsed with deionized water to 254 remove any excess pharmaceuticals adhered to their body surface and transferred to a 96-well plate. 255 A selected volume $(200 \mu \mathrm{L})$ of $10 \mathrm{mM} \mathrm{H}_{2}$ DCFDA was added to each well and the plate was then 256 incubated for $4 \mathrm{~h}$ in the dark at $20-25^{\circ} \mathrm{C}$. Fluorescence was measured using a fluorescence plate 
reader with an excitation wavelength of $350 \mathrm{~nm}$ and an emission of $600 \mathrm{~nm}$. The increase in fluorescence intensity yielded the ROS quantity compared to control.

Exposed and not exposed daphnids were homogenized in $1 \mathrm{~mL}$ sucrose buffer $(0.25 \mathrm{M}$ sucrose, 0.1 $\mathrm{M}$ Tris-HCl, $1 \mathrm{mM}$ EDTA, $\mathrm{pH} 7.4$ ) and successively centrifuged at $12.000 \mathrm{~g}$ for $15 \mathrm{~min}$ at $4^{\circ} \mathrm{C}$.

Supernatants were collected and used to determinate enzymatic activities. Protein content of the samples was quantified using the protocol described by Bradford (1976) using bovine serum albumin as standard.

CAT activity was expressed as $\mathrm{H}_{2} \mathrm{O}_{2}$ consumed ( $\mathrm{U} \cdot \mathrm{mg}^{-1}$ of protein) to convert it to $\mathrm{H}_{2} \mathrm{O}$ and $\mathrm{O}_{2}$ per minute, per mg protein at $240 \mathrm{~nm}$ (Aebi, 1984).

SOD activity was calculated by measuring the decrease in the color development of samples at 440 $\mathrm{nm}$ with the reference to the xantine oxidase/cithocrome method (Crapo et al., 1978). In particular the superoxide radical, generated from the conversion of xanthine to uric acid and $\mathrm{H}_{2} \mathrm{O}_{2}$ by xanthine oxidase, reacts with the tetrazolium salt WST-1 forming formazan.

One unit of SOD was defined as the amount of enzyme required to produce $50 \%$ inhibition in the reaction system.

GST was calculated by measuring the changes in absorbance recorded at $340 \mathrm{~nm}$ due to the conjugation of glutathione to 1-chloro-2,4-dinitrobenzene (Habig et al., 1974).

One unit of enzyme was the quantity necessary for the reduction of $1 \mu \mathrm{mol} \cdot \mathrm{L}^{-1} \mathrm{GSH}$ in $1 \mathrm{~min}$ at 37 ${ }^{\circ} \mathrm{C}$.

Test runs were performed in triplicate with additional controls including on aqueous solutions containing hydrogen peroxide supplemented with catalase, used to destroy the residual hydrogen peroxide.

\section{Results and discussion}

4.1. $U V_{254}$ photolysis: kinetic investigation 
282 The results collected from runs of $\mathrm{UV}_{254}$ photolysis of ACY in aqueous solution at three different $283 \mathrm{pH}$ values (4.5, 6.0 and 8.0) in the MCF photoreactor at varying lamp power are reported in Figs. 284 1a-e as a function of the space time. The results indicate that, for a fixed lamp power, the $\mathrm{pH}$ did not 285 affect the conversion. In fact, for these runs a half-time of about 17 seconds was recorded 286 independent of the $\mathrm{pH}$. Moreover, the analysis of the concentration $v s$ time profile demonstrated 287 that the photolysis of ACY resembled an apparent autocatalytic behavior which suggested the 288 adoption of an autocatalytic kinetic model to describe the degradation of ACY under the adopted 289 experimental conditions. Since the destruction of guanine based substrates under $\mathrm{UV}_{254}$ irradiation 290 has been ascribed to both the direct photolysis of guanine derivatives and the reaction of guanine 291 based molecules with the radical species formed during the photolytic process (Crespo-Hernandez 292 et al., 2000a,b), the simplified reaction scheme (Scheme 1) was considered for the $\mathrm{UV}_{254}$ photolysis 293 of ACY, which is a guanine derivative:

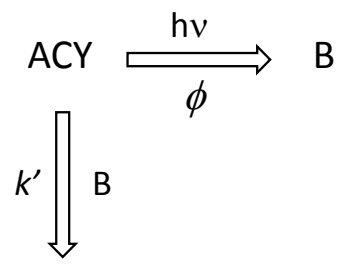

By-products

297 where B indicates a pseudo intermediate (hydrated electron, oxygen reactive species, etc.) capable 298 of reacting with ACY molecules according to a simple autocatalytic-type kinetics. The quantum 299 yield of photolysis of ACY at $254 \mathrm{~nm}\left(\phi_{A C Y}\right)$ and the kinetic constant $k$ ' were estimated through an 300 iterative method, using simultaneously the concentration data reported in Figures 1a,e to solve ODE 301 equations 1 and 2:

$$
\frac{\mathrm{d}[\mathrm{ACY}]}{\mathrm{dt}}=-P_{o} \cdot \emptyset_{\mathrm{ACY}} \cdot\left(1-\exp \left(-2.3 \cdot l_{M C F} \cdot \varepsilon_{254}^{A C Y} \cdot[\mathrm{ACY}]\right)\right)-k^{\prime} \cdot[\mathrm{ACY}] \cdot[\mathrm{B}]
$$




$$
\frac{\mathrm{d}[\mathrm{B}]}{\mathrm{dt}}=P_{o} \cdot \emptyset_{\mathrm{ACY}} \cdot\left(1-\exp \left(-2.3 \cdot l_{M C F} \cdot \varepsilon_{254}^{A C Y} \cdot[\mathrm{ACY}]\right)\right)
$$

Where $t$ is the space time in the continuous flow MCF photoreactor (the reaction or exposure time) and the term $\varepsilon_{254}^{A C Y}$ is the molar absorption coefficient at $254 \mathrm{~nm}$ for $\mathrm{ACY}$ at $\mathrm{pH} 4.5,6.0$ and 8.0 $\left(1.21 \cdot 10^{-2} \mathrm{M}^{-1} \cdot \mathrm{cm}^{-1}\right)$. This result is in agreement with the pKa values of ACY (2.27 and 9.25) (Florence, 2010).

The MATLAB routine "ode45", based on the Runge-Kutta method with adaptive step-size, was used for the optimization procedure which minimized the objective function $\sum_{j}^{m} \sum_{i}^{n}\left(y_{A C Y_{j, i}}-\right.$ $\left.c_{A C Y_{j, i}}\right)^{2}$, made by the squares of the differences between the calculated " $y$ " and experimental " $c$ " concentrations of ACY, varying the reaction time " $n$ " and for different experimental photolytic runs " $m$ ". The determined kinetic parameters that minimized the objective function were $\phi_{A C Y}=(1.62 \pm$ $\mathbf{0 . 0 7}) \cdot 10^{-3} \mathrm{~mol}_{\text {ein }}{ }^{-1}$ and $k^{\prime}=(5.64 \pm \mathbf{0 . 0 3}) \cdot 10^{-3} \mathrm{M}^{-1} \cdot \mathrm{s}^{-1}$. The comparison between experimental and calculated data, reported in Figures 1a-e including the percentage standard deviations, demonstrated close prediction of the concentration profiles of $\mathrm{ACY}$ in the MCF photoreactor.

The $\phi_{A C Y}$ value reported above has the same order of magnitude as the quantum yield of photodecomposition of other guanine derivatives, such as guanosine and 9-ethyl-guanine at similar concentrations (Crespo-Hernandez et al., 2000a), thus suggesting that the purine structure could play a fundamental role in the UV photolysis of guanine derivatives. The differences could be ascribed to a slight effect of the nature of the group attached to the 9-N on the UV-photolysis kinetics.

\section{2. $\mathrm{UV}_{254} / \mathrm{H}_{2} \mathrm{O}_{2}$ oxidation: kinetic investigation}

The results of a preliminary run carried out in the presence of hydrogen peroxide under darkness indicated that ACY was not degraded in the presence of $\mathrm{H}_{2} \mathrm{O}_{2}$ alone for reaction times up to 30 min. Photooxidation experiments of ACY by the $\mathrm{UV}_{254} / \mathrm{H}_{2} \mathrm{O}_{2}$ process were carried out under the same 
experimental conditions (i.e., $\mathrm{pH}$, lamp power and initial concentration of ACY) used in the $\mathrm{UV}_{254}$ direct photolysis runs.

The degradation profiles for ACY and $\mathrm{H}_{2} \mathrm{O}_{2}$ as a function of space time in the MCF photoreactor were modeled on the basis of a simplified reaction scheme and the mass balances listed in Table 2 .

The reaction scheme considers the consumption of ACY and hydrogen peroxide by direct photolysis (reactions 3 and 4). Hydroxyl radicals generated by $\mathrm{UV}_{254}$ photolysis of $\mathrm{H}_{2} \mathrm{O}_{2}$ can react with hydrogen peroxide (reaction 5), ACY (reaction 6) and the transformation products (reaction 7). A radical termination of peroxyl radicals was considered in the mechanism (reaction 8).

The literature reports two different values of the the kinetic constant of the reaction between hydroxyl radical and ACY $\left(k_{O H / A C Y}\right): 5.0 \cdot 10^{9} \mathrm{M}^{-1} \cdot \mathrm{s}^{-1}\left(\mathrm{pH}=9, \mathrm{~T}=18{ }^{\circ} \mathrm{C}\right.$, solar simulator $\left.\lambda>320 \mathrm{~nm}\right)$ (Prasse et al., 2015) and $1.19 \cdot 10^{10} \mathrm{M}^{-1} \cdot \mathrm{s}^{-1}(\mathrm{pH}=6-9$, lamp $\lambda>340 \mathrm{~nm}$ ) (Zhou et al., 2015) which were determined with competition kinetics in the presence of a reference compound (i.e., acetophenone, Zhou et al., 2015, and p-chloro-benzoic acid, Prasse et al., 2015). Since these $k_{O H / A C Y}$ values differed by more than $50 \%, k_{O H / A C Y}$ was determined using both numerical optimization and competition kinetics.

Specifically, the same iterative optimization procedure reported in section 4.1, using simultaneously a set of 9 photodegradation runs in distilled water, at different initial concentrations of ACY and hydrogen peroxide, $\mathrm{pH}$ and lamp power, was used for the estimation of $k_{O H / A C Y}$. The iterative method minimized the objective function (Eq. 14) that in this case was slightly modified to include the number of the reacting species $(h)$ :

$$
\Phi=\sum_{g}^{h} \sum_{j}^{m} \sum_{i}^{n}\left(y_{g, j, i}-c_{g, j, i}\right)^{2}
$$

From this method $k_{O H / A C Y}$ was determined as $(1.23 \pm \mathbf{0 . 0 7}) \cdot 10^{9} \mathrm{M}^{-1} \cdot \mathrm{s}^{-1}$. Graphical examples of the results obtained by the modeling through the optimization procedure are shown in Figures 2a-f (optimization procedure). In Figures $2 \mathrm{~g}-\mathrm{i}$ the comparison is reported between experimental and 
calculated residual ACY and $\mathrm{H}_{2} \mathrm{O}_{2}$ concentration, when the model was used in simulation mode without any further parameter adjustment (simulation mode), using the $k_{O H / A C Y}$ kinetic constant above estimated. It can be noted a good capability of the model of predicting the experimental data under the adopted conditions.

Two additional $\mathrm{UV}_{254} / \mathrm{H}_{2} \mathrm{O}_{2}$ runs (Figs. 21-m) were carried out using synthetic wastewater to further validate the kinetic results obtained. The photolytic runs were simulated using the proposed kinetic model properly modified to include the HO radical scavenging effect of the species forming the synthetic matrix (Spasiano et al., 2016). For this purpose, the pseudo-first order rate constant $\left(k_{s c a}^{\prime}=4.01 \cdot 10 \mathrm{~s}^{-1}\right)$ was considered for the reaction between the hydroxyl radicals and the scavenger species (Spasiano et al., 2016). Also in this case, a good capability of the model was still observed to predict the experimental data under the adopted conditions.

The competition kinetic method was used to estimate the $k_{O H / A C Y}$ constant in the same MCF photoreactor, to further validate the kinetic model proposed above. The method compares the ACY concentration decay to that of benzoic acid (BA) (initial concentration $2.0 \cdot 10^{-5} \mathrm{M}$ ) chosen as reference compound (Onstein et al., 1999):

$$
\operatorname{Ln}\left(\frac{[A C Y]}{[A C Y]_{0}}\right)=\frac{k_{O H / A C Y}}{k_{O H / B A}} \cdot \operatorname{Ln}\left(\frac{[B A]}{[B A]_{o}}\right) \quad k_{O H / B A}=5.9 \cdot 10^{9} \mathrm{M}^{-1} \cdot \mathrm{s}^{-1} \quad(\mathrm{pH}=6.0)
$$

An average value $k_{O H / A C Y}=(2.30 \pm \mathbf{0 . 1 1}) \cdot 10^{9} \mathrm{M}^{-1} \cdot \mathrm{s}^{-1}$ was thus calculated from $\mathrm{UV}_{254} / \mathrm{H}_{2} \mathrm{O}_{2}$ experiments carried out at $\mathrm{pH}=6.0$ and $\left[\mathrm{H}_{2} \mathrm{O}_{2}\right]_{\mathrm{o}} /[\mathrm{ACY}]_{\mathrm{o}}=20$ and at different lamp power $(4.5 \mathrm{~W}$ and $8.0 \mathrm{~W}$ ). The difference of this from the value estimated with kinetic modeling may be ascribed to the intrinsic limitations of the competition kinetics method that does not include the contribution of ACY consumption by direct photolysis. However, both $k_{O H / A C Y}$ values estimated in the present investigation were significantly lower than those previously reported in the literature (Zhou et al., 2015; Prasse et al., 2015).

\section{3. $U V_{254}$ photolysis and $U V_{254} / \mathrm{H}_{2} \mathrm{O}_{2}$ oxidation: Ecotoxicity assessment}


A battery of ecotoxicity tests on $V$. fischeri, D. magna and R. subcapitata were performed on 373 untreated and treated aqueous solutions with an initial ACY concentration of $1.2 \mathrm{mg} \cdot \mathrm{L}^{-1}$. The results showed that the inhibition of $V$. fischeri luminescence remained unchanged in the presence of the $\mathrm{UV}_{254}$ and $\mathrm{UV}_{254} / \mathrm{H}_{2} \mathrm{O}_{2}$ irradiated solutions, in comparison to the untreated solution (data not 376 shown).

377 The results obtained for D. magna (exposure time $=24$ and $48 \mathrm{~h}$ ) for the $\mathrm{UV}_{254}$ and $\mathrm{UV}_{254} / \mathrm{H}_{2} \mathrm{O}_{2}$ 378 treated and untreated samples are reported in Figures 3A,B. The samples treated with $\mathrm{UV}_{254}$ irradiation in the absence of hydrogen peroxide, initially showed an increase of immobility of daphnids at increasing $\mathrm{UV}_{254}$ dose and consequently at higher ACY conversion, suggesting an increase in acute ecotoxicity, although, this eventually decreased significantly at the highest $\mathrm{UV}_{254}$ dose. On the other hand, the acute ecotoxicity of the $\mathrm{UV}_{254} / \mathrm{H}_{2} \mathrm{O}_{2}$ treated solutions toward $D$. magna 383 was significantly lower in comparison to the samples treated with $\mathrm{UV}_{254}$ only, even at much lower $\mathrm{UV}$ doses. It is important to note that the acute ecotoxicity of the $\mathrm{UV}_{254}$ sample after complete conversion of ACY was higher than the value for the un-irradiated control sample.

The inhibition growth of $R$. subcapitata reached $32 \%, 13 \%$ and $20 \%$ at $\mathrm{UV}_{254}$ doses of 864,2356 and $4712 \mathrm{~mJ} \cdot \mathrm{cm}^{-2}$ respectively (Fig. 4), thus confirming an acute toxicological effect on the $\mathrm{UV}_{254}$ only treated samples. In contrast, a small reduction of the inhibition growth was observed for the samples treated with $\mathrm{UV}_{\mathbf{2 5 4}} / \mathrm{H}_{\mathbf{2}} \mathrm{O}_{\mathbf{2}}$ at increasing $\mathrm{UV}_{254}$ doses, which supported the beneficial effect of the $\mathrm{H}_{2} \mathrm{O}_{2}$ assisted photolytic treatment for toxicity reduction.

391 The results showed an increase of the production of ROS in all samples, that could enhance the 392 sublethal toxicity in daphnids. Aquatic organisms can in fact adapt to an increase of ROS 393 production by upregulating the activity of their antioxidant enzymes, particularly of CAT and 394 SOD which represent the first and the second line of defense against ROS (Oexle et al., 2016). An 395 evident increase of ROS production in the daphnids treated with $\mathrm{UV}_{254}$ only samples was observed 396 in comparison to the those treated with the $\mathrm{UV}_{25} / \mathrm{H}_{2} \mathrm{O}_{2}$ samples (Fig. 5A). The increase was 
recorded for UVC doses of 864 and $2356 \mathrm{~mJ} \cdot \mathrm{cm}^{-2}$ for the $U V_{254}$ process and at $280 \mathrm{~mJ} \cdot \mathrm{cm}^{-2}$ for the samples treated with $\mathrm{UV}_{254} / \mathrm{H}_{2} \mathrm{O}_{2}$.

The SOD activity resulted in significant alterations only for samples treated by $\mathrm{UV}_{254}$ (Fig. 5B). The enzyme inhibition increased when the UVC dose was increased and reached the highest inhibition at $2356 \mathrm{~mJ} \cdot \mathrm{cm}^{-2}$. No effect was observed in the samples treated with $\mathrm{UV}_{254} / \mathrm{H}_{2} \mathrm{O}_{2}$ except for samples treated with a UVC dose of $280 \mathrm{~mJ} \cdot \mathrm{cm}^{-2}$ (TOC removal degree: $28 \%$ ).

Both processes led to a significant increase of CAT activity compared to the control (Fig. 5C), since CAT is responsible for the detoxification of high levels of hydrogen peroxide, one of the most important ROS producers under oxidative stress conditions.

On the contrary, GST activity remained unchanged or decreased with both treatments as shown in Figure 5D. Probably the response patterns may be species-specific in nature, while varying in intensity response. The antioxidant enzymes can maintain cellular redox balance, alleviate the toxicological effects of ROS and protect the cells against the oxidative damage of their structures including lipid, membranes, proteins and nucleic acids (Oropesa et al., 2017).

A 21 days chronic exposure experiment was performed to determine the toxicity of 100 fold diluted untreated and treated solutions. The effects of ACY $\left(120 \mu \mathrm{g} \cdot \mathrm{L}^{-1}\right)$ and its treated samples on $D$. magna reproduction and survival are reported in Figure 6A,B.

The results of chronic toxicity showed that the $\mathrm{UV}_{254}$ treatment, even at such low concentrations of ACY, significantly decreased the survival of D. magna compared to the control group. A decrease of survival was further recorded for samples exposed at a TOC removal of less than $5 \%$ (ACY conversion degree: $45 \%$ ), probably due the presence of unconverted ACY, and at $\mathrm{UV}_{254}$ dose of $2356 \mathrm{~mJ} \cdot \mathrm{cm}^{-2}$ (ACY conversion: $90 \%$ ), due to the formation of first-generation-transformation byproducts structurally similar to ACY. At higher $\mathrm{UV}_{254}$ doses $\left(4712 \mathrm{~mJ} \cdot \mathrm{cm}^{-2}\right.$, TOC removal $\mathbf{5 \%}$ ), the survival percentage was similar to that of the control samples and always higher to that of the untreated sample. On the contrary, the ecotoxicity assessment for the $\mathrm{UV}_{254} / \mathrm{H}_{2} \mathrm{O}_{2}$ treated 
solutions reflected the results already recorded in the acute tests, revealing a marked reduction of chronic toxic effects for the exposures of the daphnids to the $\mathrm{UV}_{254} / \mathrm{H}_{2} \mathrm{O}_{2}$ samples, especially the highest $\mathrm{UV}_{254}$ doses $\left(950 \mathrm{~mJ} \cdot \mathrm{cm}^{-2}\right.$, TOC removal $77 \%$ and $1900 \mathrm{~mJ} \cdot \mathrm{cm}^{-2}$, TOC removal higher than $95 \%$ ).

As reported in Table 3, the reproduction of D. magna was completely inhibited in the organisms contacted with samples exposed to $\mathrm{UV}_{254}$ doses of $864 \mathrm{~mJ} \cdot \mathrm{cm}^{-2}$ and 2356 and in absence of $\mathrm{H}_{2} \mathrm{O}_{2}$. These results revealed that all the endpoints were different than the control solutions with an extended exposure to the treatment, thus confirming that the photoproducts formed during $\mathrm{UV}_{254}$ irradiation of aqueous ACY solutions exerted significant chronic adverse effects to D. magna at the population level. On the contrary, the total number of neonates and the number of first-brood were not statistically different among the samples untreated and treated by $\mathrm{UV}_{254} / \mathrm{H}_{2} \mathrm{O}_{2}$.

The different chemical species formed during the $\mathrm{UV}_{254}$ and the $\mathrm{UV}_{254} / \mathrm{H}_{2} \mathrm{O}_{2}$ photochemical processes could reasonably explain the observed toxicological effects. To provide a preliminary validation of this hypothesis, two samples, one from $\mathrm{UV}_{254}$ photolysis and the second from $\mathrm{UV}_{254} / \mathrm{H}_{2} \mathrm{O}_{2}$ treatment, were directly analyzed with MS-spectrometer to identify the main chemical intermediates formed, with the knowledge that a thorough identification of the transformation by-products required more sophisticated diagnostic techniques (Buchberger, 2011).

A list of molecular structures of the main intermediates that could be attributed to some peaks detected in the mass spectra for two samples is reported in Table 4. Some of the structures shown in Table 4 correspond to the chemical intermediates previously detected and reported in literature. In particular, for the $\mathrm{UV}_{254}$ photolysis, the structures II, IV and V were observed during the degradation of $\mathrm{ACY}$ by $\mathrm{TiO}_{2}$ photocatalysis at $365 \mathrm{~nm}$ (An et al., 2015) whereas the by-products $\mathrm{VII}$ and $X$ proposed for $U \mathrm{UV}_{254} / \mathrm{H}_{2} \mathrm{O}_{2}$ were the same of those observed during the photooxidation of ACY in phosphate buffer at wavelength higher than $270 \mathrm{~nm}$ (Iqbal et al., 2005).. The attribution of reliable structures to the remaining recorded 
MS signals not previously observed by others, needs further analytical assessments. However, although an uncomplete analysis is available for the products of degradation of ACY, the data collected indicated the presence of chemical species significantly different in the two samples. In particular, $\mathrm{UV}_{254} / \mathrm{H}_{2} \mathrm{O}_{2}$ process seems to lead mainly to the formation of hydroxylated imidazole-based compounds or species formed by the fragmentation of the pyrimidine ring whereas some hydroxylated ACY based intermediates are detected in the $\mathrm{UV}_{254}$ treated sample.

\section{Conclusion}

The photodegradation of ACY was investigated under $\mathrm{UV}_{254}$ irradiation in the absence and in the presence of hydrogen peroxide. A moderate rate of direct photolysis at $254 \mathrm{~nm}$ for ACY was observed with a quantum yield of $(1.62 \pm 0.073) \cdot 10^{-3} \mathrm{~mol}^{-e i n^{-1}}$ in the $\mathrm{pH}$ range $4.5-8.0$. An average value of $1.76 \cdot 10^{9} \mathrm{M}^{-1} \cdot \mathrm{s}^{-1}$ was calculated for the kinetic constant of reaction between hydroxyl radical and ACY. Considering (i) the $\mathrm{UV}_{254}$ doses typically used for the disinfection of municipal sewage treatment plant effluents, (ii) the concentration values of ACY measured in WWTP effluents, and (iii) the results collected during the kinetic and ecotoxicity assessment, the occurrence of residual photodecomposition by-products in treated effluents is very likely, and these are likely to have a high ecotoxicological index. However, the addition of appropriate amount of hydrogen peroxide during the $\mathrm{UV}_{254}$ disinfection stage would reduce this risk.

The results obtained contribute to provide useful information for a vision about the fate of ACY during the $\mathrm{UV}_{254}$ and $\mathrm{UV}_{254} / \mathrm{H}_{2} \mathrm{O}_{2}$ treatment processes and the eventual associated risks for living organisms (animals and plants) in the aquatic environment.

The results collected confirm the use of oxidative stress biomarkers as promising tool in order to evaluate the toxicological effects of environmental pollutants as early indicators in ecotoxicology.

Exposure to environmental pollutants may disrupt the balance of biological oxidant-to-antioxidant ratio in aquatic species leading to elevated levels of ROS and resulting in oxidative stress. A 
preliminary analysis on the treated samples indicated, as the main photo-transformation byproducts, the presence of hydroxylated ACY based intermediates in the $\mathrm{UV}_{254}$ treatment process, and hydroxylated imidazole based compounds or species formed by the fragmentation of the pyrimidine ring in the $\mathrm{UV}_{254} / \mathrm{H}_{2} \mathrm{O}_{2}$ treatment process.

Further efforts are required to identify the main photoproducts, to elucidate the mechanism of ACY photodegradation under UVC radiation and to evaluate possible cumulative effects of the different species occurring in STP effluents.

\section{Acknowledgements}

The Authors are grateful to ERASMUS-Mobility Student Program, and to Ing. Giulio Di Costanzo for his precious support during the experimental campaign.

\section{References}

Aebi, H., (1984) Catalase in vitro. Methods in Enzymology 6, 105-121.

An, T., An, J., Gao, Y., Li, G., Fang, H., Song, W. (2015) Photocatalytic degradation and mineralization mechanism andtoxicity assessment of antivirus drug acyclovir: Experimental and theoretical studies. Applied Catalysis B: Environmental 164, 279-287.

Asano, T. (1998) Wastewater Reclamation and Reuse, in Water Quality Management Library, Vol 10. C.R.C. Press, Boca Raton.

Azuma, T., Arima, N., Tsukada, A., Hirami, S., Matsuoka, R., Moriwake, R., Ishiuchi, H., Inoyama, T., Teranishi, Y., Yamaoka, M., Mino, Y., Hayashi, T., Fujita, Y., Masada, M. (2016) Detection of pharmaceuticals and phytochemicals together with their metabolites in hospital effluents in Japan, and their contribution to sewage treatment plant influents. Science of the Total Environment 548549, 189-197.

Bielski, B.H., Cabelli, D.E., Aruda, R.L., Ross, A.B. (1985) Reactivity of $\mathrm{HO}_{2} / \mathrm{O}_{2}$ radicals in aqueous solution. Journal of Physical and Chemical Reference Data 14, 1041-1077. 
Bradford, M.M. (1976) A rapid and sensitive method for the quantitation of microgram quantities of protein utilizing the principle of protein-dye binding. Anal. Biochem. 72, 248-254.

Bradley, P.M., Barber, L.B., Duris, J.W., Foreman, W.T., Furlong, E.T., Hubbard, L.E., Hutchinson, K.J., Keefe, S.H., Kolpin, D.W. (2014) Riverbank filtration potential of pharmaceuticals in a wastewater-impacted stream. Environmental Pollution 193, 173-180.

Bryan-Marrugo, O.L., Ramos-Jiménez, J., Barrera-Saldana, H., Rojas-Martínez, A., Vidaltamayo, R., Rivas-Estilla, A.M. (2015) History and progress of antiviral drugs: From acyclovir to directacting antiviral agents (DAAs) for Hepatitis C. Medicina Universitaria 17(68), 165-174.

Buchberger, W.W. (2011) Current approaches to trace analysis of pharmaceuticals and personal care products in the environment. Journal of Chromatography A 1218, 603-618.

Buxton, G.V., Greenstock, C.L., Helman, W.P., Ross, A.B. (1988) Critical review of rate constants for reactions of hydrated electrons, hydrogen atoms and hydroxyl radicals $(\mathrm{OH} / \mathrm{O})$ in aqueous solution. Journal of Physical and Chemical Reference Data 17, 513-886.

Canonica, S., Meunier, L., von Gunten, U. (2008) Phototransformation of selected pharmaceuticals during UV treatment of drinking water. Water Research 42, 121-128.

Conner-Kerr, T.A., Sullivan, P.K., Gaillard, J., Franklin, M.E., Jones, R.M. (1998) The effects of ultraviolet radiation on antibiotic-resistant bacteria in vitro. Ostomy Wound Manage. 44, $50-56$.

Crapo, J.D., McCord, J.M., Fridovich, I. (1978) Preparation and assay of superoxide dismutases. Methods in Enzymology 53, 382-393.

Crespo-Hernandez, C.E., Flores, S., Torres, C., Negron-Encarnacion, I., Arce, R. (2000a) Part I. Photochemical and photophysical studies of guanine derivatives: intermediates contributing to its photodestruction mechanism in aqueous solution and the participation of the electron adduct. Photochemistry and Photobiology 71(5), 534-543. 
Crespo-Hernandez, C.E., Arce, R. (2000b) Part II. Mechanism of formation of guanine as one of the major products in the $254 \mathrm{~nm}$ photolysis of guanine derivatives: concentration and $\mathrm{pH}$ effects. Photochemistry and Photobiology 71(5), 544-550.

Da Silva, L.M., Cavalcante, R.P., Cunha, R.F., Gozzi, F., Dantas, R.F., De Oliveira, S.C., Machulek, A.J. (2016) Tolfenamic acid degradation by direct photolysis and the UV-ABC/H2O2 process: factorial design, kinetics, identification of intermediates, and toxicity evaluation. Science of the Total Environment 573, 518-531.

DVGW, 1997. W 294. UV-Desinfektionsanlagen furdie Trinkwasserversorgung-Anforderungen und Prufung.

FDA (Food and Drug Administration). Guidance for Industry: Environmental Assessment of Human Drug and Biologics Application. CDER/CBER CMC 6, rev 1, 39 pp, July 1998. Available: http://www.fda.gov/cber/guidelines.htm.

Florence, A. T. (2010) An Introduction to Clinical Pharmaceutics. Ed. Pharmaceutical Press, London.

Funke, J., Prasse, C., Ternes, T.A. (2016) Identification of transformation products of antiviral drugs formed during biological wastewater treatment and their occurrence in the urban water cycle. Water Research 98, 75-83.

Galdiero, E., Siciliano, A., Maselli, V., Gesuele, R., Guida, M., Fulgione, D., Galdiero, S., Lombardi, L., Falanga, A. (2016) An integrated study on antimicrobial activity and ecotoxicity of quantum dots and quantum dots coated with the antimicrobial peptide indolicidin. International Journal of Nanomedicine 11, 4199-4211.

García-Galan, M. J., Anfruns, A., Gonzalez-Olmos, R., Rodriguez-Mozaz, S., Comas, J. (2016) Advanced oxidation of the antibiotic sulfapyridine by $\mathrm{UV} / \mathrm{H}_{2} \mathrm{O}_{2}$ : Characterization of its transformation products and ecotoxicological implications. Chemosphere 147, 451-459.

Gillman, A., Nykvist, M., Muradrasoli, S., Soderstrom, H., Wille, M., Daggfeldt, A., Brojer, C., Waldenstrom, J., Olsen, B., Jarhult, J.D. (2015) Influenza A(H7N9) virus acquires resistance- 
related neuraminidase I222T substitution when infected mallards are exposed to low levels of oseltamivir in water. Antimicrobial Agents and Chemotherapy 59(9), 5196-5202.

Goldstein, S., Aschengrau, D., Diamant, Y., Rabani, J. (2007) Photolysis of aqueous $\mathrm{H}_{2} \mathrm{O}_{2}$ : quantum yield and applications for polychromatic UV actinometry in photoreactors. Environmental Science \& Technology 41, 7486-7490.

Guo, M.T., Yuan, Q.B., Yang, J. (2013) Ultraviolet reduction of erythromycin and tetracyclineresistant heterotrophic bacteria and their resistance genes in municipal wastewater. Chemosphere 93, 2864-2868.

Habig, W.H., Pabst, M.J., Jakoby, W.B. (1974) Glutathione-S-transferases. The first step in mercapturic acid formation. Journal of Biological Chemistry 249, 7130-7139.

Hijnen, W.A.M., Beerendonk, E.F., Medema, G.J. (2006) Inactivation credit of UV radiation for viruses, bacteria and protozoan (oo)cysts in water: a review. Water Research 40 (1), 3-22.

Hill, A., Khoo, S., Fortunak, J., Simmons, B., Ford, N. (2014) Minimum costs for producing hepatitis $\mathrm{C}$ direct-acting antivirals for use in large-scale treatment access. Programs in Developing Countries. Clinical Infectious Diseases 58(7), 928-936.

Hoekstra, A.Y. (2014) Water scarcity challenges to business. Nature Climate Change 4, 318-322.

Huang, J.J., Hu, H.Y., Tang, F., Li, Y., Lu, S.Q. Lu, Y. (2011) Inactivation and reactivation of antibiotic-resistant bacteria by chlorination in secondary effluents of a municipal wastewater treatment plant. Water Research 45, 2775-2781.

Iqbal, J., Husain, A., Gupta, A. (2005) Photooxidation of acyclovir in aqueous solution.

\section{Pharmazie 60(8), 574-576}

ISO 6341:2013 Water quality: determination of the inhibition of the mobility of Daphnia magna Straus (Cladocera, Crustacea) acute toxicity test.

ISO 8692:2012 Water quality: fresh water algal growth inhibition test with unicellular green algae. 
ISO 11348-3:2007 Water quality: determination of the inhibitory effect of water samples on the light emission of Vibrio fischeri (Luminescent bacteria test), part 3: method using freeze-dried bacteria.

Jain, S., Kumar, P., Vyas, R.K., Pandit, P., Dalai, A.K. (2013) Occurrence and removal of antiviral drugs in environment: A review. Water, Air, \& Soil Pollution 224, 1410-1419.

Khan, S., Beattie, T.K., Knapp, C.W. (2016) Relationship between antibiotic- and disinfectantresistance profiles in bacteria harvested from tap water. Chemosphere 152, 132-141.

Kim, I., Yamashita, N., Tanaka, H. (2009) Photodegradation of pharmaceuticals and personal care products during $\mathrm{UV}$ and $\mathrm{UV} / \mathrm{H}_{2} \mathrm{O}_{2}$ treatments. Chemosphere 77, 518-525.

Kovacic, M., Perisic, D.J., Biosic, M., Kusic, H., Babic, S., Bozic, A.L. (2016) UV photolysis of diclofenac in water; kinetics, degradation pathway and environmental aspects. Environmental Science and Pollution Research 23, 14908-14917.

Liu, W.R., Ying, G.G., Zhao, J.L., Liu, Y.S., Hu, L.X., Yao,L., Liang, Y.Q., Tian, F. (2016) Photodegradation of the azole fungicide climbazole by ultraviolet irradiation under different conditions: Kinetics, mechanism and toxicity evaluation. Journal of Hazardous Materials 318, 794801.

Lofrano, G., Libralato, G., Adinolfi, R., Siciliano, A., Iannece, P., Guida, M., Giugni, M., Volpi Ghirardini, A., Carotenuto, M. (2016) Photocatalytic degradation of the antibiotic chloramphenicol and its by-products toxicity effects. Ecotoxicology and Environmental Safety $123,65-71$.

Ma, J., Lv, W., Chen, P., Lu, Y., Wang, F., Li, F., Yao, K., Liu, G. (2016) Photodegradation of gemfibrozil in aqueous solution under UV irradiation: kinetics, mechanism, toxicity, and degradation pathways. Environmental Science and Pollution Research 23, 14294-14306.

Marotta, R., Spasiano, D., Di Somma, I., Andreozzi, R. (2013) Photodegradation of naproxen and its photoproducts in aqueous solution at $254 \mathrm{~nm}$ : a kinetic investigation. Water Research 47, $373-$ 383. 
600

601

602

603

604

605

606

607

608

609

610

611

612

613

614

McCurry, D.L., Bear, S.E., Bae, J., Sedlak, D.L., McCarty, P.L., Mitch, W.A. (2014) Superior removal of disinfection byproduct precursors and pharmaceuticals from wastewater in a staged anaerobic fluidized membrane bioreactor compared to activated sludge. Environmental Science\& TechnologyLetters 1, 459-464.

Meckes, M.C. (1982) Effect of UV light disinfection on antibiotic-resistant coliforms in wastewater effluents. Appl. Environ. Microbiol. 43, 371-377.

Montemayor, M., Costan, A., Lucena, F., Jofre, J., Munoz, J., Dalmau, E., Mujeriego, R., Salas L. (2008) The combined performance of UV light and chlorine during reclaimed water disinfection. Water Science \& Technology 57(6), 935-940.

Munir, M., Wong, K., Xagoraraki, I. (2011) Release of antibiotic resistant bacteria and genes in the effluent and biosolids of five wastewater utilities in Michigan. Water Research 45, 681693.

Nick, K., Scholer, H.F., Mark, G., Soylemez, T., Akhlaq, M.S., Schuchmann, H.P., von Sonntag, C. (1992) Degradation of some triazine herbicides by UV radiation such as used in the UV disinfection of drinking water. Journal of Water Supply: Research and Technology Aqua 41(2), 82-87

Nicole, I., De Laat, J., Doré, M., Duguet, J.P., Bonnel, C. (1990) Use of UV radiation in water treatment: measurement of photonic flux by hydrogen peroxide actinometry. Water Research 24, 157-168.

NWRI (2012) Ultraviolet Disinfection: Guidelines for Drinking Water and Water Reuse, Third Edition. Published by National Water Research Institute.

OECD (2012) Guidelines for Testing of Chemicals. Daphnia magna Reproduction Test. OECD 211. Paris, France.

Oexle, S., Jansen, M., Pauwels, K., Sommaruga, M., De Meeste,r L., Stoks, R. (2016) Rapid evolution of antioxidant defence in a natural population of Daphnia magna. Journal of Evolutionary Biology 29, 1328-1337. 
ONorm, M. (2001). Anlagen zur Desinfektion von Wasser mittels Ultraviolett-Strahlen. Anforderungen und Prufung 5873-1.

Onstein, P., Stefan, M.I., Bolton, J.R. (1999) Competition kinetics method for the determination of rate constants for the reaction of hydroxyl radicals with organic pollutants using the $\mathrm{UV} / \mathrm{H}_{2} \mathrm{O}_{2}$ advanced oxidation technology: the rate constants for the tert-buthylformate ester and 2,4dinitrophenol. Journal of Advanced Oxidation Technologies 4(2), 231-236.

Organisation for Economic Cooperation and development (OECD), 1999. Guidelines for testing of chemicals, simulation test-aerobic sewage treatment, 303A.

Oropesa, A.L., Novais, S.C., Lemos, M.F.L. Espejo, A., Gravato, C., Beltran, F. (2017) Oxidative stress response of Daphnia magna exposed to effluents spiked with emerging contaminants under ozonation and advanced oxidation process. Environmental Science \& Pollution Research 24, 17351747.

Peng, X., Wang, C., Zhang, K., Wang, Z., Huang, Q., Yu, Y., Ou, W. (2014) Profile and behavior of antiviral drugs in aquatic environments of the Pearl River Delta, China. Science of the Total Environment 466-467, 755-761.

Pereira, V.J., Weinberg, H.S., Linden, K.G., Singer, P.C. (2007) UV degradation of pharmaceutical compounds in surface water via direct and indirect photolysis at $254 \mathrm{~nm}$. Environmental Science\& Technology 41(5), 1682-1688.

Prasse, C., Schlusener, M.P., Schulz, R., Ternes, T.A. (2010) Antiviral drugs in wastewater and surface waters: A new pharmaceutical class of environmental relevance? Environmental Science \& Technology 44, 1728-1735.

Prasse, C., Wagner, M., Schulz, R., Ternes, T.A. (2011) Biotransformation of the antiviral drugs acyclovir and penciclovir in activated sludge treatment. Environmental Science \& Technology45(7), 2761-2769. 
649 Prasse, C., Wenk, J., Jasper, J.T., Ternes, T.A., Sedlak, D.L.(2015) Co-occurrence of photochemical 650 and microbiological transformation processes in open-water unit process wetlands. Environmental 651 Science \& Technology 49, 14136-14145.

652 Reis, N.M., Li Puma, G. (2015) Novel microfluidics approach for extremely fast and efficient 653 photochemical transformations in fluoropolymer microcapillary films. ChemicalCommunications $65451,8414-8417$.

655 Richardson, S.D. (2012) Environmental mass spectrometry: emerging contaminants and current 656 issues. Analytical Chemistry 84, 747-778.

657 Richardson, S.D., Plewa, M.J.,Wagner, E.D., Schoeny, R., DeMarini, D.M. (2007) Occurrence, 658 genotoxicity, and carcinogenicity of regulated and emerging disinfection by-products in drinking 659 water: a review and roadmap for research. Mutation Research 636(1-3), 178-242.

660 Rozas, O., Vidal, C., Baeza, C., Jardim, W.F., Rossner, A., Mansilla, H.D. (2016) Organic 661 micropollutants (OMPs) in natural waters: Oxidation by $\mathrm{UV} / \mathrm{H}_{2} \mathrm{O}_{2}$ treatment and toxicity 662 assessment. Water Research 98, 109-118.

663 Russo, D., Spasiano, D., Vaccaro, M., Andreozzi, R., Li Puma, G., Reis, N.M., Marotta, R. (2016) 664 Direct photolysis of benzoylecgonine under UV irradiation at $254 \mathrm{~nm}$ in a continuous flow 665 microcapillary array photoreactor. Chemical Engineering Journal 283, 243-250.

666 Sanderson, H., Johnson, D.J., Reitsma, T., Brain, R.A., Wilson, C.J., Solomon, K.R. (2004) 667 Ranking and prioritization of environmental risks of pharmaceuticals in surface waters. Regulatory 668 Toxicology and Pharmacology 39(2), 158-183.

669 Shi, P., Jia, S., Zhang, X.X., Zhang, T., Cheng, S., Li, A. (2013) Metagenomic insights into 670 chlorination effects on microbial antibiotic resistance in drinking water. Water Research 47 , 671 111-120.

672 Singer, A.C., Nunn, M.A., Gould, E.A., Johnson, A.C. (2007) Potential risks associated with the 673 proposed widespread use of Tamiflu. Environmental Health Perspectives 115(1), 102-106. 
674 Sinha, V.R., Monika, Trehan, A., Kumar, M., Singh, S., Bhinge, J.R. (2007) Stress studies on 675 Acyclovir. Journal of Chromatographic Science 45, 319-324.

676 Spasiano, D., Russo, D., Vaccaro, M., Siciliano, A., Marotta, R., Guida, M., Reis, N.M., Li Puma, 677 G., Andreozzi, R. (2016) Removal of benzoylecgonine from water matrices through $\mathrm{UV}_{254} / \mathrm{H}_{2} \mathrm{O}_{2}$ 678 process: reaction kinetic modeling, ecotoxicity and genotoxicity assessment. Journal of Hazardous 679 Materials 318, 515-525.

680 Yuan, F., Hu, C., Hu, X., Wei, D., Chen, Y., Qu, J. (2011) Photodegradation and toxicity changes 681 of antibiotics in $\mathrm{UV}$ and $\mathrm{UV} / \mathrm{H}_{2} \mathrm{O}_{2}$ process. Journal of Hazardous Materials 185, 1256-1263.

682 Zhou, C., Chen, J., Xie, Q., Wei, X., Zhang, Y., Fu, Z. (2015) Photolysis of three antiviral drugs 683 acyclovir, zidovudine and lamivudine in surface freshwater and seawater. Chemosphere 138, 792684797. 


\section{Photodegradation and ecotoxicology of acyclovir in water under $\mathrm{UV}_{254}$ and}

$2 \quad \mathrm{UV}_{254} / \mathrm{H}_{2} \mathrm{O}_{2}$ processes

3

4 Danilo Russo ${ }^{\mathrm{a}}$, Antonietta Siciliano ${ }^{\mathrm{b}}$, Marco Guida ${ }^{\mathrm{b}}$, Emilia Galdiero ${ }^{\mathrm{b}}$, Angela Amoresano ${ }^{\mathrm{c}}$,

5 Roberto Andreozzi ${ }^{\mathrm{a}}$, Nuno M. Reis ${ }^{\mathrm{d}, \mathrm{e}}$, Gianluca Li Puma ${ }^{\mathrm{e}, \dot{\hbar}}$ and Raffaele Marotta ${ }^{\mathrm{a}, \dagger}$

6

8 Napoli Federico II, p.le V. Tecchio 80, Napoli, Italy.

9

${ }^{a}$ Dipartimento di Ingegneria Chimica, dei Materiali e della Produzione Industriale, Università di

${ }^{\mathrm{b}}$ Dipartimento di Biologia, Università di Napoli Federico II, Complesso Universitario Monte Sant'Angelo, via Cinthia 4, Napoli, Italy.

${ }^{\mathrm{c}}$ Dipartimento di Scienze Chimiche, Università di Napoli Federico II, Complesso Universitario Monte Sant'Angelo, via Cinthia 4, Napoli, Italy.

${ }^{\mathrm{d}}$ Department of Chemical Engineering, University of Bath, Claverton Down, Bath BA2 7AY, UK.

${ }^{\mathrm{e}}$ Environmental Nanocatalysis \& Photoreaction Engineering Department of Chemical Engineering, Loughborough University, Loughborough LE11 3TU, UK.

$\dagger$ Corresponding author: Tel.: +39(0)817682968, fax: +39815936936. E-mail address: rmarotta@unina.it (R. Marotta).

* Corresponding author: Tel.: +44(0)1509222510, fax: +44(0)1509223923. E-mail address: G.Lipuma@lboro.ac.uk (G. Li Puma).

\section{Abstract}

The photochemical and ecotoxicological fate of acyclovir (ACY) through $\mathrm{UV}_{254}$ direct photolysis and in the presence of hydroxyl radicals $\left(\mathrm{UV}_{254} / \mathrm{H}_{2} \mathrm{O}_{2}\right.$ process) were investigated in a microcapillary film (MCF) array photoreactor, which provided ultrarapid and accurate photochemical reaction 
kinetics. The UVC phototransformation of $\mathrm{ACY}$ was found to be unaffected by $\mathrm{pH}$ in the range from 4.5 to 8.0 and resembled an apparent autocatalytic reaction. The proposed mechanism included the formation of a photochemical intermediate $\left(\phi_{A C Y}=(1.62 \pm 0.07) \cdot 10^{-3} \mathrm{~mol}^{-e^{-1}}\right)^{-1}$ that further reacted with ACY to form by-products $\left(k^{\prime}=(5.64 \pm 0.03) \cdot 10^{-3} \mathrm{M}^{-1} \cdot \mathrm{s}^{-1}\right)$. The photolysis of $\mathrm{ACY}$ in the presence of hydrogen peroxide accelerated the removal of ACY as a result of formation of hydroxyl radicals. The kinetic constant for the reaction of $\mathrm{OH}$ radicals with ACY $\left(k_{O H / A C Y}\right)$ determined with the kinetic modeling method was $(1.23 \pm 0.07) \cdot 10^{9} \mathrm{M}^{-1} \cdot \mathrm{s}^{-1}$ and with the competition kinetics method was $(2.30 \pm 0.11) \cdot 10^{9} \mathrm{M}^{-1} \cdot \mathrm{s}^{-1}$ with competition kinetics. The acute and chronic effects of the treated aqueous mixtures on different living organisms (Vibrio fischeri, Raphidocelis subcapitata, D. magna) revealed significantly lower toxicity for the samples treated with $\mathrm{UV}_{254} / \mathrm{H}_{2} \mathrm{O}_{2}$ in comparison to those collected during $\mathrm{UV}_{254}$ treatment. This result suggests that the addition of moderate quantity of hydrogen peroxide $\left(30-150 \mathrm{mg} \cdot \mathrm{L}^{-1}\right)$ might be a useful strategy to reduce the ecotoxicity of $\mathrm{UV}_{254}$ based sanitary engineered systems for water reclamation.

Keywords: UVC, hydrogen peroxide photolysis, microreactor, ecotoxicity, water reuse, acyclovir removal.

\section{Introduction}

Water reclamation and water reuse is becoming increasingly common in industrialized countries with high water demands and in water stressed regions characterized by considerable scarcity of freshwater (Hoekstra, 2014). The most common treatment method for water reuse is chlorination at typical dosages ranging from 5 to $20 \mathrm{mg} / \mathrm{L}$ with a maximum of two hours of contact time (Asano, 1998). However, concerns related to (i) the adverse impacts of chlorine on irrigated crops, (ii) the high ecotoxicity of chlorinated by-products (DBPs) formed during the chlorination stage (Richardson et al., 2007) and (iii) the survival of antibiotics resistant bacteria during chlorination 
(Khan et al., 2016) with a possible selection of some antibiotic resistance genes in the wastewater microbial community (Huang et al., 2011) should drive the transition from chlorine disinfection to other more ecofriendly suitable methods. UV radiation treatment (especially $\mathrm{UVC}, \lambda<280 \mathrm{~nm}$ ) produces a high sterilization efficiency (Montemayor et al., 2008) and could represent a viable alternative to chlorination for the disinfection and reuse of effluents from wastewater treatment plant (WWTP) for irrigation (i.e., after membrane filtration and/or reverse osmosis) or for aquifer recharge. Numerous wastewater sites have adopted UVC treatment for effluents disinfection. For example, Florida and California have favored wastewater reuse and adopted specific regulations on reclamation technologies through UV disinfection processes. UVC doses (fluence) ranging from 50 $\mathrm{mJ} \cdot \mathrm{cm}^{-2}$ to $150 \mathrm{~mJ} \cdot \mathrm{cm}^{-2}$ have been suggested to efficiently inactivate pathogens accounting for the variability in the effluent composition (NWRI, 2012), although German and Austrian regulations (DVGW,1997; ONorm, 2001) suggest the use of $40 \mathrm{~mJ} \cdot \mathrm{cm}^{-2}$ UVC fluence to eliminate a large variety of bacteria and viruses (Conner-Kerr et al., 1998). Even though UV disinfection has been reported highly effective in the reduction of antibiotic resistance bacteria (ARB), particularly in comparison to chlorination (Shi et al., 2013; Hijnen et al., 2006), other investigations have demonstrated that UV disinfection may not contribute to the significant reduction of selected ARB, such as tetracycline-and sulfonamide-resistant bacteria (Munir et al., 2011; Meckes, 1982) thus indicating a plausible selectivity of UV on ARB (Guo et al., 2013).

Moreover, numerous studies have suggested that under the recommended UVC doses several biorefractory xenobiotics, particularly pharmaceuticals and personal care products generally occurring in municipal discharges and partially removed in WWTPs, may undergo photochemical transformations induced by UVC irradiation (Canonica et al., 2008; Nick et al., 1992; Pereira et al, 2007; Kim et al., 2009; Ma et al., 2016; Kovacic et al., 2016; Liu et al., 2016; Marotta et al., 2013) which may generate by-products with high ecotoxicity (Rozas et al., 2016; Yuan et al., 2011). For these reasons, the use of hydrogen peroxide during UVC disinfection $\left(\mathrm{UV}_{254} / \mathrm{H}_{2} \mathrm{O}_{2}\right)$ which produces highly reactive radical species, has been proposed as a viable treatment for effective removal of 
micropollutant and $\mathrm{ARB}$ and, in consequence, for the reduction of the ecotoxicity risk (GarcíaGalan et al., 2016; Melo da Silva et al., 2016).

Among the emerging Pharmaceuticals and Personal Care Products detected in WWTP effluents, antiviral drugs play a leading role (Richardson, 2012; Jain et al., 2013) due to their scarce biodegradability (Funke et al., 2016) and increased usage during the last decade, particularly for the treatment of viral diseases and for the prevention of pandemic outbreaks (Hill et al., 2014). Moreover, antiviral drugs have been considered as some of the most hazardous therapeutic substances exerting high toxicity towards biota, such as crustaceans, fish and algae (Sanderson et al., 2004). The presence of antiviral drugs in the environment raises considerable concern regarding their potential effect on the ecosystem, with the potential of developing antiviral drug resistance, in analogy to the development of antibiotic resistant bacteria (Singer et al., 2007; Gillman et al., 2015). Acyclovir (ACY) is one of the oldest and most widely used antiviral drug for treating two common viral infections (chickenpox-zoster and herpes simplex) and it is also prescribed to patients with weakened immune systems in order to control viral infections (i.e., viral conjunctivitis) (BryanMarrugo et al., 2015). ACY has been recently detected in different WWTP effluents as well as in surface water at level of few nanograms per liter up to over one micrograms per liter (Table 1).

The photodegradation pathways of ACY under artificial and natural solar light irradiation have been recently investigated (Zhou et al., 2015; Prasse et al., 2015). However, there is a lack of investigations on the photochemical transformation of ACY under $\mathrm{UV}_{254}$ and $\mathrm{UV}_{254} / \mathrm{H}_{2} \mathrm{O}_{2}$ treatments and on the simultaneous ecotoxicological assessments of highly diluted treated solutions containing ACY.

More information is needed to determine the effectiveness of $\mathrm{UV}_{254}$ assisted processes on the removal of ACY from aqueous solutions and the impact that these processes may have on the structure of aquatic communities and on the ecosystem dynamics.

The use of microcapillary flow photoreactors has recently been proposed to intensify the treatment of substances that are either highly priced, scarcely commercially available or controlled substances 
such as illicit drugs or selected pharmaceuticals (Reis and Li Puma, 2015; Russo et al., 2016). In contrast to conventional laboratory photochemical systems which require relatively larger volume of liquid, photochemical treatments in microphotoreactors are carried out in a highly controlled environment with minimal sample volumes (of the order of few $\mathrm{mL}$ ), the sufficient amount to generate samples for subsequent analysis. Furthermore, photochemical transformations in microphotoreactors are executed at extremely short residence times (of the order of seconds) in comparison to conventional laboratory photoreactors, resulting in an efficient use of time and resources.

Under this background, in this study we investigated the degradation kinetics of ACY in distilled water under $\mathrm{UV}_{254}$ and $\mathrm{UV}_{254} / \mathrm{H}_{2} \mathrm{O}_{2}$ irradiation by means of a microcapillary film (MCF) array photoreactor and we evaluated the acute and chronic ecotoxicity of highly diluted treated samples using a range of selected organisms, to provide important information regarding the photolysis of ACY in $\mathrm{UV}_{254}$ based sanitary engineered systems for water reclamation. The toxicity was assessed considering a battery of toxicity tests (Aliivibrio fischeri, Raphidocelis subcapitata, Daphnia magna) and endpoints (bioluminescence, growth inhibition, immobilization, survival, reproduction and biomarker) including three trophic and phylogenetic levels (Lofrano et al., 2016).

The battery of toxicity tests proposed were sensitive indicators of toxic pollutants, and also determined the great diversity of potential stress-receptor that could result from pharmaceuticals and their byproducts entering the environment (FDA, 1998).

\section{Materials and methods}

\subsection{Materials}

Hydrogen peroxide (30\% v/v), ACY (pharmaceutical secondary standard), methanol ( $\geq 99.9 \% \mathrm{v} / \mathrm{v})$, formic acid $(>99 \% \mathrm{w} / \mathrm{w})$, benzoic acid $(\geq 99.5 \% \mathrm{w} / \mathrm{w})$, orthophosphoric acid $\left(85 \% \mathrm{w} / \mathrm{w}\right.$ in $\left.\mathrm{H}_{2} \mathrm{O}\right)$, sodium hydroxide (>98\% w/w), perchloric acid (70\% v/v), catalase from Micrococcus lysodeikticus and reagents for ecotoxicity tests were purchased from Sigma-Aldrich. An aqueous mixture of 
peptone $(32 \mathrm{ppm})$, meat extract $(22 \mathrm{ppm})$, urea $(6 \mathrm{ppm}), \mathrm{K}_{2} \mathrm{HPO}_{4}(28 \mathrm{ppm}), \mathrm{CaCl}_{2} \cdot \mathrm{H}_{2} \mathrm{O}(4 \mathrm{ppm})$, $\mathrm{NaCl}(7 \mathrm{ppm})$ and $\mathrm{Mg}_{2} \mathrm{SO}_{4}(0.6 \mathrm{ppm})$ was used for the preparation of a synthetic wastewater according to the OECD Guidelines (Organisation for Economic Cooperation and development, 1999). The substances were purchased from Sigma-Aldrich and used as received. Milli-Q water was used as solvent in analytical determinations and experiments.

\subsection{Analytical methods}

The concentration of hydrogen peroxide, ACY, and benzoic acid was measured by HPLC (1100 Agilent) equipped with a Gemini 5u C6-Phenyl 110 (Phenomenex) reverse phase column and a diode array detector. The mobile phase was a mixture of $93 \%$ aqueous orthophosphoric acid (10 $\mathrm{mM}$ ) and $7 \%$ methanol flowing at $8.0 \cdot 10^{-4} \mathrm{~L} \cdot \mathrm{min}^{-1}$. The $\mathrm{pH}$ of the aqueous solutions was adjusted with $\mathrm{NaOH}$ or $\mathrm{HClO}_{4}$ and measured with an Accumet Basic AB-10 pH-meter. The molar absorption coefficient of ACY was estimated using a Perkin Elmer UV/VIS spectrometer (mod. Lambda 35). Total organic carbon (TOC) was monitored by a TOC analyzer (Shimadzu 5000 A). MS analysis was performed by direct injection on Agilent 6230 TOF LC/MS coupled with Agilent HPLC system (1260 Series). The mobile phase was a mixture of methanol (10\% v/v) and formic acid $(0.1 \% \mathrm{v} / \mathrm{v})$ aqueous solution at flow rate of $0.4 \mathrm{~mL} \cdot \mathrm{min}^{-1}$ and the injection volume of samples was $20 \mu \mathrm{L}$. The MS source was an electrospray ionization (ESI) interface in the positive ion mode with capillary voltage of $3500 \mathrm{~V}$, gas temperature at $325^{\circ} \mathrm{C}$, dry gas $\left(\mathrm{N}_{2}\right)$ flow at $8 \mathrm{~L} \cdot \mathrm{min}^{-1}$ and the nebulizer at $35 \mathrm{psi}$. The MS spectra were acquired in a mass range of $100-3000 \mathrm{~m} / \mathrm{z}$ with a rate of 1 spectrum/s, time of $1000 \mathrm{~ms} / \mathrm{spectrum}$ and transient/spectrum of 9905.

\section{Experimental apparatus and procedures}

\subsection{MCF array photoreactor}

The degradation kinetics of ACY by $\mathrm{UV}_{254}$ and $\mathrm{UV}_{254} / \mathrm{H}_{2} \mathrm{O}_{2}$ were investigated in a MCF array photoreactor described elsewhere (Reis et al., 2015; Russo et al., 2016). Briefly, the photoreactor 
(Lamina Dielectrics Ltd) consisted of ten $\mathrm{UV}_{254}$ transparent microcapillaries of fluorinated polymer characterized by a mean hydraulic diameter of $195 \mu \mathrm{m}$. The microcapillaries were coiled around a UV monochromatic (254 nm) lamp (Germicidal G8T5) in the region with uniform emission. Experiments were carried out at room temperature $\left(\sim 25^{\circ} \mathrm{C}\right)$ in continuous flow through the reactor at different space times, using capillaries of different length exposed to the UV lamp irradiation. The flow rate through the MCF was $6.0 \cdot 10^{-4} \mathrm{~L} \cdot \mathrm{min}^{-1}$. Aqueous samples were collected from the MCF outlet, and rapidly analyzed by HPLC. At the end of each experimental run, the $\mathrm{pH}$ of the solutions was unchanged. The initial concentration of ACY used in the experiments ranged between $2.05 \cdot 10^{-5} \mathrm{~mol} \cdot \mathrm{L}^{-1}$ and $4.67 \cdot 10^{-5} \mathrm{~mol} \cdot \mathrm{L}^{-1}$.

The lamp irradiance was varied by changing the nominal power from $4.5 \mathrm{~W}$ to $8.0 \mathrm{~W}$ using a variable power supply unit. The photon fluxes per unit volume emitted by the UV lamp $\left(P_{o}\right)$ for each power setting, estimated by $\mathrm{H}_{2} \mathrm{O}_{2}$ actinometry (Nicole et al, 1990; Goldstein et al., 2007), were $1.92 \cdot 10^{-2}$ ein $\cdot(\mathrm{s} \cdot \mathrm{L})^{-1}$ (nominal power $8.0 \mathrm{~W}$ ) and $1.27 \cdot 10^{-2}$ ein $\cdot(\mathrm{s} \cdot \mathrm{L})^{-1}$ (nominal power $4.5 \mathrm{~W}$ ). The MCF average optical path length $\left(l_{M C F}\right)$ was $154 \mu \mathrm{m}$. All the runs were carried out in duplicate. The data collected were used to estimate the kinetic unknown parameters (quantum yield of direct photolysis at $254 \mathrm{~nm}$ of ACY and kinetic constant of hydroxyl radical attack to ACY).

\subsection{Cylindrical batch photoreactor}

A cylindrical batch photoreactor $\left(\mathrm{V}_{\mathrm{b}}=0.480 \mathrm{~L}\right)$, equipped with a low-pressure mercury monochromatic lamp (Helios Italquartz, HGL10T5L, 17W nominal power emitting at $254 \mathrm{~nm}$ ), was used to provide large sample volumes required for the ecotoxicity tests at varying treatment times (i.e., different $\mathrm{UV}_{254}$ fluence). The $\mathrm{UV}_{254}$ dose $\left(\mathrm{mJ} \cdot \mathrm{cm}^{-2}\right)$ was calculated as the average photon fluence rate multiplied by the treatment time. The average photon fluence rate emitted by the UV lamp at $254 \mathrm{~nm}$ was $4.7 \mathrm{~mW} \cdot \mathrm{cm}^{-2}$ (UVC DELTA OHM radiometer). The experimental device was described elsewhere (Spasiano et al., 2016). 


\subsection{Ecotoxicity assessment}

182 Reconstituted aqueous solution $(\mathrm{pH}=7.8 \pm 0.2)$, was used as dilution water for cladoceran toxicity 183 tests: $\mathrm{CaCl}_{2} \cdot 2 \mathrm{H}_{2} \mathrm{O}\left(290 \mathrm{mg} \cdot \mathrm{L}^{-1}\right), \mathrm{MgSO}_{4} \cdot 7 \mathrm{H}_{2} \mathrm{O}\left(120 \mathrm{mg} \cdot \mathrm{L}^{-1}\right), \mathrm{NaHCO}_{3}\left(65 \mathrm{mg} \cdot \mathrm{L}^{-1}\right), \mathrm{KCl}(6$ $\left.184 \mathrm{mg} \cdot \mathrm{L}^{-1}\right)$. Different salts were used for the preparation of algal test medium: $\mathrm{CaCl}_{2} \cdot 2 \mathrm{H}_{2} \mathrm{O}\left(18 \mathrm{mg} \cdot \mathrm{L}^{-}\right.$ 185 $\left.{ }^{1}\right), \mathrm{MgSO}_{4} \cdot 7 \mathrm{H}_{2} \mathrm{O}\left(15 \mathrm{mg} \cdot \mathrm{L}^{1}\right), \mathrm{NH}_{4} \mathrm{Cl}\left(15 \mathrm{mg} \cdot \mathrm{L}^{-1}\right), \mathrm{MgCl}_{2} \cdot 6 \mathrm{H}_{2} \mathrm{O}\left(12 \mathrm{mg} \cdot \mathrm{L}^{-1}\right), \mathrm{KH}_{2} \mathrm{PO}_{4}\left(1.6 \mathrm{mg} \cdot \mathrm{L}^{-1}\right)$, $\mathrm{FeCl}_{3} \cdot 6 \mathrm{H}_{2} \mathrm{O}\left(0.08 \mathrm{mg} \cdot \mathrm{L}^{-1}\right), \mathrm{Na}_{2}$ EDTA $2 \mathrm{H}_{2} \mathrm{O}\left(0.1 \mathrm{mg} \cdot \mathrm{L}^{-1}\right), \mathrm{H}_{3} \mathrm{BO}_{3}\left(0.185 \mathrm{mg} \cdot \mathrm{L}^{-1}\right), \mathrm{MnCl}_{2} \cdot 4 \mathrm{H}_{2} \mathrm{O}$ $\left(0.415 \mathrm{mg} \cdot \mathrm{L}^{-1}\right), \mathrm{ZnCl}_{2}\left(0.003 \mathrm{mg} \cdot \mathrm{L}^{-1}\right), \mathrm{CoCl}_{2} \cdot 6 \mathrm{H}_{2} \mathrm{O}\left(0.0015 \mathrm{mg} \cdot \mathrm{L}^{-1}\right), \mathrm{Na}_{2} \mathrm{MoO}_{4} \cdot 2 \mathrm{H}_{2} \mathrm{O}\left(7.0 \cdot 10^{-3}\right.$ $\left.\mathrm{mg} \cdot \mathrm{L}^{-1}\right), \mathrm{CuCl}_{2} \cdot 2 \mathrm{H}_{2} \mathrm{O}\left(1.0 \cdot 10^{-5} \mathrm{mg} \cdot \mathrm{L}^{-1}\right)$. Reconstitution solution, osmotic adjusting solution (OAS) and diluent $(\mathrm{NaCl} 2 \%)$ were the reagents used in Vibrio fischeri toxicity test (Strategic diagnostics Inc. SDI).

The enzymatic assays chosen to evaluate oxidative stress were ROS (reactive oxygen species) content using 2,7- dichlorodihydrofluorescein ( $\mathrm{H}_{2}$ DCFDA) and activities of SOD (superoxide dismutase), CAT (catalase) and GST (glutathione transferase) that were measured using respective assay kits according to the manufactorer's instruction's (Sigma Aldrich). All determinations were quantified spectrophotometrically.

V. fischeri, R. subcapitata and acute D. magna assays were conducted with an initial ACY concentration of $1.2 \mathrm{mg} \cdot \mathrm{L}^{-1}$ and on its related $\mathrm{UV}_{254}$ and $\mathrm{UV}_{254} / \mathrm{H}_{2} \mathrm{O}_{2}$ treated solutions. Chronic toxicity and oxidative stress tests on Daphnia magna were performed starting on untreated and treated solutions diluted by 100 fold, in order to assess any differences at sub lethal concentration levels. Negative and positive controls were included in each experiment. The significance of differences of toxicity between the treated samples and controls was assessed by the analysis of variance (ANOVA) considering a significance threshold level always set at 5\%. For higher variance 
possible, toxicity was expressed as median effective concentration $\left(\mathrm{EC}_{50}\right)$ with $95 \%$ confidence limit values. Otherwise, toxicity was expressed as percentage of effect (PE, \%).

\subsubsection{Organisms maintenance and monitoring}

Freeze-dried Vibrio fischeri (strain NRRL-B-11177) cells were reconstituted with reagent diluent at $4{ }^{\circ} \mathrm{C}$. Raphidocelis subcapitata were cultured in ISO medium (ISO, 2012) at $23 \pm 2{ }^{\circ} \mathrm{C}$ with continuous 4500 lux light and aeration (0.2 mm filtered air). Daphnia magna were cultured at $20 \pm$ $1{ }^{\circ} \mathrm{C}$, with a 16:8 light/dark photoperiod in ISO water (ISO, 2012).

Luminescence $V$. fischeri measurements were performed with Microtox ${ }^{\circledR}$ Model 500 Toxicity Analyzer from Microbics Corporation (AZUR Environmental) equipped with a 30 well incubated at $15 \pm 1{ }^{\circ} \mathrm{C}$ and with excitation source at $490 \mathrm{~nm}$ wavelength.

$R$. subcapitata density was determined by an indirect procedure using a spectrophotometer (Hach Lange DR5000) and cuvette $(5 \mathrm{~cm})$. D. magna viability, mobility and growth were observed with a stereomicroscope (LEICA EZ4-HD).

\subsubsection{Bacteria toxicity test}

The inhibitory effect of ACY samples on the light emission of V. fischeri (strain NRRL-B-11177) was evaluated with the 11348-3:2007 ISO method (ISO, 2007). Tests were carried out on an ACY concentration of $1.2 \mathrm{mg} \cdot \mathrm{L}^{-1}$ and on its related treated by-products solutions. OAS was added to each sample to ensure that the final $\mathrm{NaCl}$ concentration was above $2.0 \%$. The initial light output from each cuvette containing reconstituted freeze-dried $V$. fischeri was recorded. The test solutions were then added and after 30 minutes exposure, the final light output was measured. Positive control tests for $V$. fischeri were carried out with $\mathrm{C}_{6} \mathrm{H}_{4} \mathrm{Cl}_{2} \mathrm{O}\left(\mathrm{EC}_{50}=4.1 \pm 2.2 \mathrm{mg} \cdot \mathrm{L}^{-1}\right)$.

\subsubsection{Algae toxicity test}


The R. subcapitata bioassay was conducted following the guidelines ISO 8692 (ISO, 2012). Three replicates were included for each sample. The replicates were inoculated with $10^{4}$ algal cells $\cdot \mathrm{mL}^{-1}$ and incubated for $72 \mathrm{~h}$ at $23 \pm 2{ }^{\circ} \mathrm{C}$ under continuous illumination (irradiance range of 120-60 $\mu$ ein $\left.\cdot \mathrm{m}^{-2} \cdot \mathrm{s}^{-1}\right)$. The algal biomass exposed to the samples was compared with the algal biomass in the negative control. Positive control tests for $R$. subcapitata were carried out with $\mathrm{K}_{2} \mathrm{Cr}_{2} \mathrm{O}_{7}\left(\mathrm{EC}_{50}=1 \pm\right.$ $\left.0.2 \mathrm{mg} \cdot \mathrm{L}^{-1}\right)$

\subsubsection{Crustaceans toxicity test}

Acute toxicity tests with D. magna were carried out according to ISO 6341 (ISO, 2013). Newborn daphnids $\left(<24 \mathrm{~h}\right.$ old) were exposed in four replicates for $24 \mathrm{~h}$ and $48 \mathrm{~h}$ at $20 \pm 1{ }^{\circ} \mathrm{C}$. Toxicity was expressed as percentage of immobilized organisms. Positive control tests for D. magna were carried out with $\mathrm{K}_{2} \mathrm{Cr}_{2} \mathrm{O}_{7}\left(48 \mathrm{~h}, \mathrm{EC}_{50}=0.6 \pm 0.1 \mathrm{mg} \cdot \mathrm{L}^{-1}\right)$.

The D. magna chronic bioassay was carried out according to the guideline OECD 211 (OECD, 2012). Ten $D$. magna neonates $(<24$ h hold) were used and individually placed for each treatment in beakers containing $50 \mathrm{ml}$ of the test solutions, renewed every two other days. Organisms exposed for 21 days with ACY solutions were then fed one day with $R$. subcapitata $\left(10^{7}\right.$ cell $\left.\cdot \mathrm{mL}^{-1}\right)$. Survival, reproduction and growth were observed daily, and newborns were discarded from beakers.

The amount of ROS produced in D. magna was determined using 2,7-dichlorodihydrofluorescein ( $\mathrm{H}_{2}$ DCFDA, Sigma Aldrich) using the method previously reported (Galdiero et al., 2016). After 48 $\mathrm{h}$ of exposure, each exposed and not exposed living daphnids were rinsed with deionized water to remove any excess pharmaceuticals adhered to their body surface and transferred to a 96-well plate. A selected volume $(200 \mu \mathrm{L})$ of $10 \mathrm{mM} \mathrm{H}_{2}$ DCFDA was added to each well and the plate was then incubated for $4 \mathrm{~h}$ in the dark at $20-25^{\circ} \mathrm{C}$. Fluorescence was measured using a fluorescence plate 
reader with an excitation wavelength of $350 \mathrm{~nm}$ and an emission of $600 \mathrm{~nm}$. The increase in 254 fluorescence intensity yielded the ROS quantity compared to control.

255 Exposed and not exposed daphnids were homogenized in $1 \mathrm{~mL}$ sucrose buffer $(0.25 \mathrm{M}$ sucrose, 0.1 $256 \mathrm{M}$ Tris-HCl, $1 \mathrm{mM}$ EDTA, $\mathrm{pH}$ 7.4) and successively centrifuged at $12.000 \mathrm{~g}$ for $15 \mathrm{~min}$ at $4^{\circ} \mathrm{C}$.

257 Supernatants were collected and used to determinate enzymatic activities. Protein content of the 258 samples was quantified using the protocol described by Bradford (1976) using bovine serum 259 albumin as standard.

260 CAT activity was expressed as $\mathrm{H}_{2} \mathrm{O}_{2}$ consumed (U.mg ${ }^{-1}$ of protein) to convert it to $\mathrm{H}_{2} \mathrm{O}$ and $\mathrm{O}_{2}$ per 261 minute, per mg protein at $240 \mathrm{~nm}$ (Aebi, 1984).

262 SOD activity was calculated by measuring the decrease in the color development of samples at 440 $263 \mathrm{~nm}$ with the reference to the xantine oxidase/cithocrome method (Crapo et al., 1978). In particular 264 the superoxide radical, generated from the conversion of xanthine to uric acid and $\mathrm{H}_{2} \mathrm{O}_{2}$ by xanthine 265 oxidase, reacts with the tetrazolium salt WST-1 forming formazan.

266 One unit of SOD was defined as the amount of enzyme required to produce $50 \%$ inhibition in the 267 reaction system.

268 GST was calculated by measuring the changes in absorbance recorded at $340 \mathrm{~nm}$ due to the 269 conjugation of glutathione to 1-chloro-2,4-dinitrobenzene (Habig et al., 1974).

270 One unit of enzyme was the quantity necessary for the reduction of $1 \mu \mathrm{mol} \cdot \mathrm{L}^{-1} \mathrm{GSH}$ in $1 \mathrm{~min}$ at 37 $271{ }^{\circ} \mathrm{C}$.

272 Test runs were performed in triplicate with additional controls including on aqueous solutions 273 containing hydrogen peroxide supplemented with catalase, used to destroy the residual hydrogen 274 peroxide. 
278 The results collected from runs of $\mathrm{UV}_{254}$ photolysis of ACY in aqueous solution at three different $279 \mathrm{pH}$ values (4.5, 6.0 and 8.0) in the MCF photoreactor at varying lamp power are reported in Figs. 280 1a-e as a function of the space time. The results indicate that, for a fixed lamp power, the $\mathrm{pH}$ did not 281 affect the conversion. In fact, for these runs a half-time of about 17 seconds was recorded 282 independent of the $\mathrm{pH}$. Moreover, the analysis of the concentration vs time profile demonstrated 283 that the photolysis of ACY resembled an apparent autocatalytic behavior which suggested the 284 adoption of an autocatalytic kinetic model to describe the degradation of ACY under the adopted 285 experimental conditions. Since the destruction of guanine based substrates under $\mathrm{UV}_{254}$ irradiation 286 has been ascribed to both the direct photolysis of guanine derivatives and the reaction of guanine 287 based molecules with the radical species formed during the photolytic process (Crespo-Hernandez 288 et al., 2000a,b), the simplified reaction scheme (Scheme 1) was considered for the $U_{254}$ photolysis 289 of ACY, which is a guanine derivative:

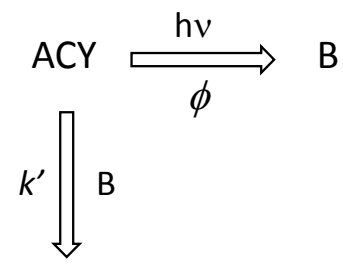

By-products

where B indicates a pseudo intermediate (hydrated electron, oxygen reactive species, etc.) capable of reacting with ACY molecules according to a simple autocatalytic-type kinetics. The quantum yield of photolysis of ACY at $254 \mathrm{~nm}\left(\phi_{A C Y}\right)$ and the kinetic constant $k$ ' were estimated through an 296 iterative method, using simultaneously the concentration data reported in Figures 1a,e to solve ODE 297 equations 1 and 2:

$$
\frac{\mathrm{d}[\mathrm{ACY}]}{\mathrm{dt}}=-P_{o} \cdot \emptyset_{\mathrm{ACY}} \cdot\left(1-\exp \left(-2.3 \cdot l_{M C F} \cdot \varepsilon_{254}^{A C Y} \cdot[\mathrm{ACY}]\right)\right)-k^{\prime} \cdot[\mathrm{ACY}] \cdot[\mathrm{B}]
$$




$$
\frac{\mathrm{d}[\mathrm{B}]}{\mathrm{dt}}=P_{o} \cdot \emptyset_{\mathrm{ACY}} \cdot\left(1-\exp \left(-2.3 \cdot l_{M C F} \cdot \varepsilon_{254}^{A C Y} \cdot[\mathrm{ACY}]\right)\right)
$$

Where $t$ is the space time in the continuous flow MCF photoreactor (the reaction or exposure time) and the term $\varepsilon_{254}^{A C Y}$ is the molar absorption coefficient at $254 \mathrm{~nm}$ for $\mathrm{ACY}$ at $\mathrm{pH} 4.5,6.0$ and 8.0 $\left(1.21 \cdot 10^{-2} \mathrm{M}^{-1} \cdot \mathrm{cm}^{-1}\right)$. This result is in agreement with the pKa values of ACY (2.27 and 9.25) (Florence, 2010).

The MATLAB routine "ode45", based on the Runge-Kutta method with adaptive step-size, was used for the optimization procedure which minimized the objective function $\sum_{j}^{m} \sum_{i}^{n}\left(y_{A C Y_{j, i}}-\right.$ $\left.c_{A C Y_{j, i}}\right)^{2}$, made by the squares of the differences between the calculated " $y$ " and experimental " $c$ " concentrations of ACY, varying the reaction time " $n$ " and for different experimental photolytic runs " $m$ ". The determined kinetic parameters that minimized the objective function were $\phi_{A C Y}=(1.62 \pm$ $0.07) \cdot 10^{-3} \mathrm{~mol}^{-e i n^{-1}}$ and $k^{\prime}=(5.64 \pm 0.03) \cdot 10^{-3} \mathrm{M}^{-1} \cdot \mathrm{s}^{-1}$. The comparison between experimental and calculated data, reported in Figures 1a-e including the percentage standard deviations, demonstrated close prediction of the concentration profiles of ACY in the MCF photoreactor.

The $\phi_{A C Y}$ value reported above has the same order of magnitude as the quantum yield of photodecomposition of other guanine derivatives, such as guanosine and 9-ethyl-guanine at similar concentrations (Crespo-Hernandez et al., 2000a), thus suggesting that the purine structure could play a fundamental role in the UV photolysis of guanine derivatives. The differences could be ascribed to a slight effect of the nature of the group attached to the 9-N on the UV-photolysis kinetics.

\section{2. $\mathrm{UV}_{254} / \mathrm{H}_{2} \mathrm{O}_{2}$ oxidation: kinetic investigation}

The results of a preliminary run carried out in the presence of hydrogen peroxide under darkness indicated that ACY was not degraded in the presence of $\mathrm{H}_{2} \mathrm{O}_{2}$ alone for reaction times up to 30 min. Photooxidation experiments of ACY by the $\mathrm{UV}_{254} / \mathrm{H}_{2} \mathrm{O}_{2}$ process were carried out under the same 
experimental conditions (i.e., $\mathrm{pH}$, lamp power and initial concentration of ACY) used in the $\mathrm{UV}_{254}$ direct photolysis runs.

The degradation profiles for ACY and $\mathrm{H}_{2} \mathrm{O}_{2}$ as a function of space time in the MCF photoreactor were modeled on the basis of a simplified reaction scheme and the mass balances listed in Table 2.

The reaction scheme considers the consumption of ACY and hydrogen peroxide by direct photolysis (reactions 3 and 4). Hydroxyl radicals generated by $\mathrm{UV}_{254}$ photolysis of $\mathrm{H}_{2} \mathrm{O}_{2}$ can react with hydrogen peroxide (reaction 5), ACY (reaction 6) and the transformation products (reaction 7). A radical termination of peroxyl radicals was considered in the mechanism (reaction 8).

The literature reports two different values of the the kinetic constant of the reaction between hydroxyl radical and ACY $\left(k_{O H / A C Y}\right): 5.0 \cdot 10^{9} \mathrm{M}^{-1} \cdot \mathrm{s}^{-1}\left(\mathrm{pH}=9, \mathrm{~T}=18{ }^{\circ} \mathrm{C}\right.$, solar simulator $\left.\lambda>320 \mathrm{~nm}\right)$ (Prasse et al., 2015) and $1.19 \cdot 10^{10} \mathrm{M}^{-1} \cdot \mathrm{s}^{-1}(\mathrm{pH}=6-9$, lamp $\lambda>340 \mathrm{~nm}$ ) (Zhou et al., 2015) which were determined with competition kinetics in the presence of a reference compound (i.e., acetophenone, Zhou et al., 2015, and p-chloro-benzoic acid, Prasse et al., 2015). Since these $k_{O H / A C Y}$ values differed by more than $50 \%, k_{O H / A C Y}$ was determined using both numerical optimization and competition kinetics.

Specifically, the same iterative optimization procedure reported in section 4.1, using simultaneously a set of 9 photodegradation runs in distilled water, at different initial concentrations of ACY and hydrogen peroxide, $\mathrm{pH}$ and lamp power, was used for the estimation of $k_{O H / A C Y}$. The iterative method minimized the objective function (Eq. 14) that in this case was slightly modified to include the number of the reacting species $(h)$ :

$$
\Phi=\sum_{g}^{h} \sum_{j}^{m} \sum_{i}^{n}\left(y_{g, j, i}-c_{g, j, i}\right)^{2}
$$

From this method $k_{O H / A C Y}$ was determined as $(1.23 \pm 0.07) \cdot 10^{9} \mathrm{M}^{-1} \cdot \mathrm{s}^{-1}$. Graphical examples of the results obtained by the modeling through the optimization procedure are shown in Figures 2a-f (optimization procedure). In Figures $2 \mathrm{~g}$ - $\mathrm{i}$ the comparison is reported between experimental and 
calculated residual ACY and $\mathrm{H}_{2} \mathrm{O}_{2}$ concentration, when the model was used in simulation mode without any further parameter adjustment (simulation mode), using the $k_{O H / A C Y}$ kinetic constant above estimated. It can be noted a good capability of the model of predicting the experimental data under the adopted conditions.

Two additional $\mathrm{UV}_{254} / \mathrm{H}_{2} \mathrm{O}_{2}$ runs (Figs. 2l-m) were carried out using synthetic wastewater to further validate the kinetic results obtained. The photolytic runs were simulated using the proposed kinetic model properly modified to include the HO radical scavenging effect of the species forming the synthetic matrix (Spasiano et al., 2016). For this purpose, the pseudo-first order rate constant $\left(\mathrm{k}_{\mathrm{sca}}=\right.$ 4.01.10 $\mathrm{s}^{-1}$ ) was considered for the reaction between the hydroxyl radicals and the scavenger species (Spasiano et al., 2016). Also in this case, a good capability of the model was still observed to predict the experimental data under the adopted conditions.

The competition kinetic method was used to estimate the $k_{O H / A C Y}$ constant in the same MCF photoreactor, to further validate the kinetic model proposed above. The method compares the ACY concentration decay to that of benzoic acid (BA) (initial concentration $2.0 \cdot 10^{-5} \mathrm{M}$ ) chosen as reference compound (Onstein et al., 1999):

$$
\operatorname{Ln}\left(\frac{[A C Y]}{[A C Y]_{0}}\right)=\frac{k_{O H / A C Y}}{k_{O H / B A}} \cdot \operatorname{Ln}\left(\frac{[B A]}{[B A]_{o}}\right) \quad k_{O H / B A}=5.9 \cdot 10^{9} \mathrm{M}^{-1} \cdot \mathrm{s}^{-1} \quad(\mathrm{pH}=6.0)
$$

An average value $k_{O H / A C Y}=(2.30 \pm 0.11) \cdot 10^{9} \mathrm{M}^{-1} \cdot \mathrm{s}^{-1}$ was thus calculated from $\mathrm{UV}_{254} / \mathrm{H}_{2} \mathrm{O}_{2}$ experiments carried out at $\mathrm{pH}=6.0$ and $\left[\mathrm{H}_{2} \mathrm{O}_{2}\right]_{\mathrm{o}} /[\mathrm{ACY}]_{\mathrm{o}}=20$ and at different lamp power $(4.5 \mathrm{~W}$ and $8.0 \mathrm{~W}$ ). The difference of this from the value estimated with kinetic modeling may be ascribed to the intrinsic limitations of the competition kinetics method that does not include the contribution of ACY consumption by direct photolysis. However, both $k_{O H / A C Y}$ values estimated in the present investigation were significantly lower than those previously reported in the literature (Zhou et al., 2015; Prasse et al., 2015).

\section{3. $U V_{254}$ photolysis and $U V_{254} / \mathrm{H}_{2} \mathrm{O}_{2}$ oxidation: Ecotoxicity assessment}


A battery of ecotoxicity tests on $V$. fischeri, D. magna and $R$. subcapitata were performed on untreated and treated aqueous solutions with an initial ACY concentration of $1.2 \mathrm{mg} \cdot \mathrm{L}^{-1}$. The results showed that the inhibition of $V$. fischeri luminescence remained unchanged in the presence of the $\mathrm{UV}_{254}$ and $\mathrm{UV}_{254} / \mathrm{H}_{2} \mathrm{O}_{2}$ irradiated solutions, in comparison to the untreated solution (data not shown).

The results obtained for D. magna (exposure time $=24$ and $48 \mathrm{~h}$ ) for the $\mathrm{UV}_{254}$ and $\mathrm{UV}_{254} / \mathrm{H}_{2} \mathrm{O}_{2}$ treated and untreated samples are reported in Figures $3 \mathrm{~A}, \mathrm{~B}$. The samples treated with $\mathrm{UV}_{254}$ irradiation in the absence of hydrogen peroxide, initially showed an increase of immobility of daphnids at increasing $\mathrm{UV}_{254}$ dose and consequently at higher ACY conversion, suggesting an increase in acute ecotoxicity, although, this eventually decreased significantly at the highest $\mathrm{UV}_{254}$ dose. On the other hand, the acute ecotoxicity of the $\mathrm{UV}_{254} / \mathrm{H}_{2} \mathrm{O}_{2}$ treated solutions toward D. magna was significantly lower in comparison to the samples treated with $\mathrm{UV}_{254}$ only, even at much lower UV doses. It is important to note that the acute ecotoxicity of the $\mathrm{UV}_{254}$ sample after complete conversion of ACY was higher than the value for the un-irradiated control sample.

The inhibition growth of $R$. subcapitata reached $32 \%, 13 \%$ and $20 \%$ at $\mathrm{UV}_{254}$ doses of 864,2356 and $4712 \mathrm{~mJ} \cdot \mathrm{cm}^{-2}$ respectively (Fig. 4), thus confirming an acute toxicological effect on the $\mathrm{UV}_{254}$ only treated samples. In contrast, a small reduction of the inhibition growth was observed for the samples treated with $\mathrm{UV}_{254} / \mathrm{H}_{2} \mathrm{O}_{2}$ at increasing $\mathrm{UV}_{254}$ doses, which supported the beneficial effect of the $\mathrm{H}_{2} \mathrm{O}_{2}$ assisted photolytic treatment for toxicity reduction.

The results showed an increase of the production of ROS in all samples, that could enhance the sublethal toxicity in daphnids. Aquatic organisms can in fact adapt to an increase of ROS production by upregulating the activity of their antioxidant enzymes, particularly of CAT and SOD which represent the first and the second line of defense against ROS (Oexle et al., 2016). An evident increase of ROS production in the daphnids treated with $\mathrm{UV}_{254}$ only samples was observed in comparison to the those treated with the $\mathrm{UV}_{254} / \mathrm{H}_{2} \mathrm{O}_{2}$ samples (Fig. 5A). The increase was 
recorded for UVC doses of 864 and $2356 \mathrm{~mJ} \cdot \mathrm{cm}^{-2}$ for the $\mathrm{UV}_{254}$ process and at $280 \mathrm{~mJ} \cdot \mathrm{cm}^{-2}$ for the samples treated with $\mathrm{UV}_{254} / \mathrm{H}_{2} \mathrm{O}_{2}$.

The SOD activity resulted in significant alterations only for samples treated by $\mathrm{UV}_{254}$ (Fig. 5B). The enzyme inhibition increased when the UVC dose was increased and reached the highest inhibition at $2356 \mathrm{~mJ} \cdot \mathrm{cm}^{-2}$. No effect was observed in the samples treated with $\mathrm{UV}_{254} / \mathrm{H}_{2} \mathrm{O}_{2}$ except for samples treated with a UVC dose of $280 \mathrm{~mJ} \cdot \mathrm{cm}^{-2}$ (TOC removal degree: $28 \%$ ).

Both processes led to a significant increase of CAT activity compared to the control (Fig. 5C), since CAT is responsible for the detoxification of high levels of hydrogen peroxide, one of the most important ROS producers under oxidative stress conditions.

On the contrary, GST activity remained unchanged or decreased with both treatments as shown in Figure 5D. Probably the response patterns may be species-specific in nature, while varying in intensity response. The antioxidant enzymes can maintain cellular redox balance, alleviate the toxicological effects of ROS and protect the cells against the oxidative damage of their structures including lipid, membranes, proteins and nucleic acids (Oropesa et al., 2017).

A 21 days chronic exposure experiment was performed to determine the toxicity of 100 fold diluted untreated and treated solutions. The effects of ACY $\left(120 \mu \mathrm{g} \cdot \mathrm{L}^{-1}\right)$ and its treated samples on $D$. magna reproduction and survival are reported in Figure 6A,B.

The results of chronic toxicity showed that the $\mathrm{UV}_{254}$ treatment, even at such low concentrations of ACY, significantly decreased the survival of D. magna compared to the control group. A decrease of survival was further recorded for samples exposed at a TOC removal of less than 5\% (ACY conversion degree: $45 \%$ ), probably due the presence of unconverted ACY, and at $\mathrm{UV}_{254}$ dose of $2356 \mathrm{~mJ} \cdot \mathrm{cm}^{-2}$ (ACY conversion: $90 \%$ ), due to the formation of first-generation-transformation byproducts structurally similar to ACY. At higher $\mathrm{UV}_{254}$ doses $\left(4712 \mathrm{~mJ} \cdot \mathrm{cm}^{-2}\right.$, TOC removal $\left.\sim 5 \%\right)$, the survival percentage was similar to that of the control samples and always higher to that of the untreated sample. On the contrary, the ecotoxicity assessment for the $\mathrm{UV}_{254} / \mathrm{H}_{2} \mathrm{O}_{2}$ treated solutions 
reflected the results already recorded in the acute tests, revealing a marked reduction of chronic toxic effects for the exposures of the daphnids to the $\mathrm{UV}_{254} / \mathrm{H}_{2} \mathrm{O}_{2}$ samples, especially the highest $\mathrm{UV}_{254}$ doses $\left(950 \mathrm{~mJ} \cdot \mathrm{cm}^{-2}\right.$, TOC removal $77 \%$ and $1900 \mathrm{~mJ} \cdot \mathrm{cm}^{-2}$, TOC removal higher than $\left.95 \%\right)$.

As reported in Table 3, the reproduction of D. magna was completely inhibited in the organisms contacted with samples exposed to $\mathrm{UV}_{254}$ doses of $864 \mathrm{~mJ} \cdot \mathrm{cm}^{-2}$ and 2356 and in absence of $\mathrm{H}_{2} \mathrm{O}_{2}$. These results revealed that all the endpoints were different than the control solutions with an extended exposure to the treatment, thus confirming that the photoproducts formed during $\mathrm{UV}_{254}$ irradiation of aqueous ACY solutions exerted significant chronic adverse effects to D. magna at the population level. On the contrary, the total number of neonates and the number of first-brood were not statistically different among the samples untreated and treated by $\mathrm{UV}_{254} / \mathrm{H}_{2} \mathrm{O}_{2}$.

The different chemical species formed during the $\mathrm{UV}_{254}$ and the $\mathrm{UV}_{254} / \mathrm{H}_{2} \mathrm{O}_{2}$ photochemical processes could reasonably explain the observed toxicological effects. To provide a preliminary validation of this hypothesis, two samples, one from $\mathrm{UV}_{254}$ photolysis and the second from $\mathrm{UV}_{254} / \mathrm{H}_{2} \mathrm{O}_{2}$ treatment, were directly analyzed with MS-spectrometer to identify the main chemical intermediates formed, with the knowledge that a thorough identification of the transformation byproducts required more sophisticated diagnostic techniques (Buchberger, 2011).

A list of molecular structures of the main intermediates that could be attributed to some peaks detected in the mass spectra for two samples is reported in Table 4. Some of the structures shown in Table 4 correspond to the chemical intermediates previously detected and reported in literature. In particular, for the $\mathrm{UV}_{254}$ photolysis, the structures II, IV and $\mathrm{V}$ were observed during the degradation of ACY by $\mathrm{TiO}_{2}$ photocatalysis at $365 \mathrm{~nm}$ (An et al., 2015) whereas the by-products VII and $\mathrm{X}$ proposed for $\mathrm{UV}_{254} / \mathrm{H}_{2} \mathrm{O}_{2}$ were the same of those observed during the photooxidation of ACY in phosphate buffer at wavelength higher than $270 \mathrm{~nm}$ (Iqbal et al., 2005).. The attribution of reliable structures to the remaining recorded MS signals not previously observed by others, needs further analytical assessments. However, although an uncomplete analysis is available for the products of degradation of ACY, the data collected indicated the presence of chemical species 
significantly different in the two samples. In particular, $\mathrm{UV}_{254} / \mathrm{H}_{2} \mathrm{O}_{2}$ process seems to lead mainly to the formation of hydroxylated imidazole-based compounds or species formed by the fragmentation of the pyrimidine ring whereas some hydroxylated ACY based intermediates are detected in the $\mathrm{UV}_{254}$ treated sample.

\section{Conclusion}

The photodegradation of ACY was investigated under $\mathrm{UV}_{254}$ irradiation in the absence and in the presence of hydrogen peroxide. A moderate rate of direct photolysis at $254 \mathrm{~nm}$ for ACY was observed with a quantum yield of $(1.62 \pm 0.073) \cdot 10^{-3} \mathrm{~mol}^{-e i n^{-1}}$ in the $\mathrm{pH}$ range $4.5-8.0$. An average value of $1.76 \cdot 10^{9} \mathrm{M}^{-1} \cdot \mathrm{s}^{-1}$ was calculated for the kinetic constant of reaction between hydroxyl radical and ACY. Considering (i) the $\mathrm{UV}_{254}$ doses typically used for the disinfection of municipal sewage treatment plant effluents, (ii) the concentration values of ACY measured in WWTP effluents, and (iii) the results collected during the kinetic and ecotoxicity assessment, the occurrence of residual photodecomposition by-products in treated effluents is very likely, and these are likely to have a high ecotoxicological index. However, the addition of appropriate amount of hydrogen peroxide during the $\mathrm{UV}_{254}$ disinfection stage would reduce this risk.

The results obtained contribute to provide useful information for a vision about the fate of ACY during the $\mathrm{UV}_{254}$ and $\mathrm{UV}_{254} / \mathrm{H}_{2} \mathrm{O}_{2}$ treatment processes and the eventual associated risks for living organisms (animals and plants) in the aquatic environment.

The results collected confirm the use of oxidative stress biomarkers as promising tool in order to evaluate the toxicological effects of environmental pollutants as early indicators in ecotoxicology. Exposure to environmental pollutants may disrupt the balance of biological oxidant-to-antioxidant ratio in aquatic species leading to elevated levels of ROS and resulting in oxidative stress. A preliminary analysis on the treated samples indicated, as the main photo-transformation byproducts, the presence of hydroxylated ACY based intermediates in the $\mathrm{UV}_{254}$ treatment process, 
and hydroxylated imidazole based compounds or species formed by the fragmentation of the pyrimidine ring in the $\mathrm{UV}_{254} / \mathrm{H}_{2} \mathrm{O}_{2}$ treatment process.

Further efforts are required to identify the main photoproducts, to elucidate the mechanism of ACY photodegradation under UVC radiation and to evaluate possible cumulative effects of the different species occurring in STP effluents.

\section{Acknowledgements}

The Authors are grateful to ERASMUS-Mobility Student Program, and to Ing. Giulio Di Costanzo for his precious support during the experimental campaign.

\section{References}

Aebi, H., (1984) Catalase in vitro. Methods in Enzymology 6, 105-121.

An, T., An, J., Gao, Y., Li, G., Fang, H., Song, W. (2015) Photocatalytic degradation and mineralization mechanism andtoxicity assessment of antivirus drug acyclovir: Experimental and theoretical studies. Applied Catalysis B: Environmental 164, 279-287.

Asano, T. (1998) Wastewater Reclamation and Reuse, in Water Quality Management Library, Vol 10. C.R.C. Press, Boca Raton.

Azuma, T., Arima, N., Tsukada, A., Hirami, S., Matsuoka, R., Moriwake, R., Ishiuchi, H., Inoyama, T., Teranishi, Y., Yamaoka, M., Mino, Y., Hayashi, T., Fujita, Y., Masada, M. (2016) Detection of pharmaceuticals and phytochemicals together with their metabolites in hospital effluents in Japan, and their contribution to sewage treatment plant influents. Science of the Total Environment 548549, 189-197.

Bielski, B.H., Cabelli, D.E., Aruda, R.L., Ross, A.B. (1985) Reactivity of $\mathrm{HO}_{2} / \mathrm{O}_{2}$ radicals in aqueous solution. Journal of Physical and Chemical Reference Data 14, 1041-1077.

Bradford, M.M. (1976) A rapid and sensitive method for the quantitation of microgram quantities of protein utilizing the principle of protein-dye binding. Anal. Biochem. 72, 248-254. 
Bradley, P.M., Barber, L.B., Duris, J.W., Foreman, W.T., Furlong, E.T., Hubbard, L.E., Hutchinson, K.J., Keefe, S.H., Kolpin, D.W. (2014) Riverbank filtration potential of pharmaceuticals in a wastewater-impacted stream. Environmental Pollution 193, 173-180.

Bryan-Marrugo, O.L., Ramos-Jiménez, J., Barrera-Saldana, H., Rojas-Martínez, A., Vidaltamayo, R., Rivas-Estilla, A.M. (2015) History and progress of antiviral drugs: From acyclovir to directacting antiviral agents (DAAs) for Hepatitis C. Medicina Universitaria 17(68), 165-174.

Buchberger, W.W. (2011) Current approaches to trace analysis of pharmaceuticals and personal care products in the environment. Journal of Chromatography A 1218, 603-618.

Buxton, G.V., Greenstock, C.L., Helman, W.P., Ross, A.B. (1988) Critical review of rate constants for reactions of hydrated electrons, hydrogen atoms and hydroxyl radicals $(\mathrm{OH} / \mathrm{O})$ in aqueous solution. Journal of Physical and Chemical Reference Data 17, 513-886.

Canonica, S., Meunier, L., von Gunten, U. (2008) Phototransformation of selected pharmaceuticals during UV treatment of drinking water. Water Research 42, 121-128.

Conner-Kerr, T.A., Sullivan, P.K., Gaillard, J., Franklin, M.E., Jones, R.M. (1998) The effects of ultraviolet radiation on antibiotic-resistant bacteria in vitro. Ostomy Wound Manage. 44, 50-56.

Crapo, J.D., McCord, J.M., Fridovich, I. (1978) Preparation and assay of superoxide dismutases. Methods in Enzymology 53, 382-393.

Crespo-Hernandez, C.E., Flores, S., Torres, C., Negron-Encarnacion, I., Arce, R. (2000a) Part I. Photochemical and photophysical studies of guanine derivatives: intermediates contributing to its photodestruction mechanism in aqueous solution and the participation of the electron adduct. Photochemistry and Photobiology 71(5), 534-543.

Crespo-Hernandez, C.E., Arce, R. (2000b) Part II. Mechanism of formation of guanine as one of the major products in the $254 \mathrm{~nm}$ photolysis of guanine derivatives: concentration and $\mathrm{pH}$ effects. Photochemistry and Photobiology 71(5), 544-550.

Da Silva, L.M., Cavalcante, R.P., Cunha, R.F., Gozzi, F., Dantas, R.F., De Oliveira, S.C., Machulek, A.J. (2016) Tolfenamic acid degradation by direct photolysis and the UV-ABC/H2O2 
process: factorial design, kinetics, identification of intermediates, and toxicity evaluation. Science of the Total Environment 573, 518-531.

DVGW, 1997. W 294. UV-Desinfektionsanlagen furdie Trinkwasserversorgung-Anforderungen und Prufung.

FDA (Food and Drug Administration). Guidance for Industry: Environmental Assessment of Human Drug and Biologics Application. CDER/CBER CMC 6, rev 1, 39 pp, July 1998. Available: http://www.fda.gov/cber/guidelines.htm.

Florence, A. T. (2010) An Introduction to Clinical Pharmaceutics. Ed. Pharmaceutical Press, London.

Funke, J., Prasse, C., Ternes, T.A. (2016) Identification of transformation products of antiviral drugs formed during biological wastewater treatment and their occurrence in the urban water cycle. Water Research 98, 75-83.

Galdiero, E., Siciliano, A., Maselli, V., Gesuele, R., Guida, M., Fulgione, D., Galdiero, S., Lombardi, L., Falanga, A. (2016) An integrated study on antimicrobial activity and ecotoxicity of quantum dots and quantum dots coated with the antimicrobial peptide indolicidin. International Journal of Nanomedicine 11, 4199-4211.

García-Galan, M. J., Anfruns, A., Gonzalez-Olmos, R., Rodriguez-Mozaz, S., Comas, J. (2016) Advanced oxidation of the antibiotic sulfapyridine by $\mathrm{UV} / \mathrm{H}_{2} \mathrm{O}_{2}$ : Characterization of its transformation products and ecotoxicological implications. Chemosphere 147, 451-459.

Gillman, A., Nykvist, M., Muradrasoli, S., Soderstrom, H., Wille, M., Daggfeldt, A., Brojer, C., Waldenstrom, J., Olsen, B., Jarhult, J.D. (2015) Influenza A(H7N9) virus acquires resistancerelated neuraminidase I222T substitution when infected mallards are exposed to low levels of oseltamivir in water. Antimicrobial Agents and Chemotherapy 59(9), 5196-5202.

Goldstein, S., Aschengrau, D., Diamant, Y., Rabani, J. (2007) Photolysis of aqueous $\mathrm{H}_{2} \mathrm{O}_{2}$ : quantum yield and applications for polychromatic UV actinometry in photoreactors. Environmental Science \& Technology 41, 7486-7490. 
547 Guo, M.T., Yuan, Q.B., Yang, J. (2013) Ultraviolet reduction of erythromycin and 548 tetracyclineresistant heterotrophic bacteria and their resistance genes in municipal wastewater. 549 Chemosphere 93, 2864-2868.

550 Habig, W.H., Pabst, M.J., Jakoby, W.B. (1974) Glutathione-S-transferases. The first step in 551 mercapturic acid formation. Journal of Biological Chemistry 249, 7130-7139.

552 Hijnen, W.A.M., Beerendonk, E.F., Medema, G.J. (2006) Inactivation credit of UV radiation for 553 viruses, bacteria and protozoan (oo)cysts in water: a review. Water Research 40 (1), 3-22.

554 Hill, A., Khoo, S., Fortunak, J., Simmons, B., Ford, N. (2014) Minimum costs for producing 555 hepatitis $\mathrm{C}$ direct-acting antivirals for use in large-scale treatment access. Programs in Developing 556 Countries. Clinical Infectious Diseases 58(7), 928-936.

557 Hoekstra, A.Y. (2014) Water scarcity challenges to business. Nature Climate Change 4, 318-322.

558 Huang, J.J., Hu, H.Y., Tang, F., Li, Y., Lu, S.Q. Lu, Y. (2011) Inactivation and reactivation of 559 antibiotic-resistant bacteria by chlorination in secondary effluents of a municipal wastewater 560 treatment plant. Water Research 45, 2775-2781.

561 Iqbal, J., Husain, A., Gupta, A. (2005) Photooxidation of acyclovir in aqueous solution. Pharmazie $562 \quad 60(8), 574-576$

563 ISO 6341:2013 Water quality: determination of the inhibition of the mobility of Daphnia magna 564 Straus (Cladocera, Crustacea) acute toxicity test.

565 ISO 8692:2012 Water quality: fresh water algal growth inhibition test with unicellular green algae.

566 ISO 11348-3:2007 Water quality: determination of the inhibitory effect of water samples on the 567 light emission of Vibrio fischeri (Luminescent bacteria test), part 3: method using freeze-dried 568 bacteria.

569 Jain, S., Kumar, P., Vyas, R.K., Pandit, P., Dalai, A.K. (2013) Occurrence and removal of antiviral 570 drugs in environment: A review. Water, Air, \& Soil Pollution 224, 1410-1419.

571 Khan, S., Beattie, T.K., Knapp, C.W. (2016) Relationship between antibiotic- and disinfectant572 resistance profiles in bacteria harvested from tap water. Chemosphere 152, 132-141. 
573 Kim, I., Yamashita, N., Tanaka, H. (2009) Photodegradation of pharmaceuticals and personal care 574 products during $\mathrm{UV}$ and $\mathrm{UV} / \mathrm{H}_{2} \mathrm{O}_{2}$ treatments. Chemosphere 77, 518-525.

575 Kovacic, M., Perisic, D.J., Biosic, M., Kusic, H., Babic, S., Bozic, A.L. (2016) UV photolysis of 576 diclofenac in water; kinetics, degradation pathway and environmental aspects. Environmental 577 Science and Pollution Research 23, 14908-14917.

578 Liu, W.R., Ying, G.G., Zhao, J.L., Liu, Y.S., Hu, L.X., Yao,L., Liang, Y.Q., Tian, F. (2016) 579 Photodegradation of the azole fungicide climbazole by ultraviolet irradiation under different 580 conditions: Kinetics, mechanism and toxicity evaluation. Journal of Hazardous Materials 318, 794581801.

582 Lofrano, G., Libralato, G., Adinolfi, R., Siciliano, A., Iannece, P., Guida, M., Giugni, M., Volpi 583 Ghirardini, A., Carotenuto, M. (2016) Photocatalytic degradation of the antibiotic chloramphenicol 584 and its by-products toxicity effects. Ecotoxicology and Environmental Safety 123, 65-71.

585 Ma, J., Lv, W., Chen, P., Lu, Y., Wang, F., Li, F., Yao, K., Liu, G. (2016) Photodegradation of 586 gemfibrozil in aqueous solution under UV irradiation: kinetics, mechanism, toxicity, and 587 degradation pathways. Environmental Science and Pollution Research 23, 14294-14306.

588 Marotta, R., Spasiano, D., Di Somma, I., Andreozzi, R. (2013) Photodegradation of naproxen and 589 its photoproducts in aqueous solution at $254 \mathrm{~nm}$ : a kinetic investigation. Water Research 47, $373-$ 590383.

591 McCurry, D.L., Bear, S.E., Bae, J., Sedlak, D.L., McCarty, P.L., Mitch, W.A. (2014) Superior 592 removal of disinfection byproduct precursors and pharmaceuticals from wastewater in a staged 593 anaerobic fluidized membrane bioreactor compared to activated sludge. Environmental Science\& 594 TechnologyLetters 1, 459-464.

595 Meckes, M.C. (1982) Effect of UV light disinfection on antibiotic-resistant coliforms in wastewater 596 effluents. Appl. Environ. Microbiol. 43, 371-377. 
Montemayor, M., Costan, A., Lucena, F., Jofre, J., Munoz, J., Dalmau, E., Mujeriego, R., Salas L. 598 (2008) The combined performance of UV light and chlorine during reclaimed water disinfection. 599 Water Science \& Technology 57(6), 935-940.

600 Munir, M., Wong, K., Xagoraraki, I. (2011) Release of antibiotic resistant bacteria and genes in the 601 effluent and biosolids of five wastewater utilities in Michigan. Water Research 45, 681-693.

602 Nick, K., Scholer, H.F., Mark, G., Soylemez, T., Akhlaq, M.S., Schuchmann, H.P., von Sonntag, C. 603 (1992) Degradation of some triazine herbicides by UV radiation such as used in the UV disinfection 604 of drinking water. Journal of Water Supply: Research and Technology Aqua 41(2), 82-87

605 Nicole, I., De Laat, J., Doré, M., Duguet, J.P., Bonnel, C. (1990) Use of UV radiation in water 606 treatment: measurement of photonic flux by hydrogen peroxide actinometry. Water Research 24 , $607 \quad 157-168$.

608 NWRI (2012) Ultraviolet Disinfection: Guidelines for Drinking Water and Water Reuse, Third 609 Edition. Published by National Water Research Institute.

610 OECD (2012) Guidelines for Testing of Chemicals. Daphnia magna Reproduction Test. OECD 211. 611 Paris, France.

612 Oexle, S., Jansen, M., Pauwels, K., Sommaruga, M., De Meeste,r L., Stoks, R. (2016) Rapid 613 evolution of antioxidant defence in a natural population of Daphnia magna. Journal of Evolutionary 614 Biology 29, 1328-1337.

615 ONorm, M. (2001). Anlagen zur Desinfektion von Wasser mittels Ultraviolett-Strahlen. 616 Anforderungen und Prufung 5873-1.

617 Onstein, P., Stefan, M.I., Bolton, J.R. (1999) Competition kinetics method for the determination of 618 rate constants for the reaction of hydroxyl radicals with organic pollutants using the $\mathrm{UV} / \mathrm{H}_{2} \mathrm{O}_{2}$ 619 advanced oxidation technology: the rate constants for the tert-buthylformate ester and 2,4620 dinitrophenol. Journal of Advanced Oxidation Technologies 4(2), 231-236.

621 Organisation for Economic Cooperation and development (OECD), 1999. Guidelines for testing of 622 chemicals, simulation test-aerobic sewage treatment, 303A. 
Oropesa, A.L., Novais, S.C., Lemos, M.F.L. Espejo, A., Gravato, C., Beltran, F. (2017) Oxidative stress response of Daphnia magna exposed to effluents spiked with emerging contaminants under ozonation and advanced oxidation process. Environmental Science \& Pollution Research 24, 17351747.

Peng, X., Wang, C., Zhang, K., Wang, Z., Huang, Q., Yu, Y., Ou, W. (2014) Profile and behavior of antiviral drugs in aquatic environments of the Pearl River Delta, China. Science of the Total Environment 466-467, 755-761.

Pereira, V.J., Weinberg, H.S., Linden, K.G., Singer, P.C. (2007) UV degradation of pharmaceutical compounds in surface water via direct and indirect photolysis at $254 \mathrm{~nm}$. Environmental Science\& Technology 41(5), 1682-1688.

Prasse, C., Schlusener, M.P., Schulz, R., Ternes, T.A. (2010) Antiviral drugs in wastewater and surface waters: A new pharmaceutical class of environmental relevance? Environmental Science \& Technology 44, 1728-1735.

Prasse, C., Wagner, M., Schulz, R., Ternes, T.A. (2011) Biotransformation of the antiviral drugs acyclovir and penciclovir in activated sludge treatment. Environmental Science \& Technology45(7), 2761-2769.

Prasse, C., Wenk, J., Jasper, J.T., Ternes, T.A., Sedlak, D.L.(2015) Co-occurrence of photochemical and microbiological transformation processes in open-water unit process wetlands. Environmental Science \& Technology 49, 14136-14145.

Reis, N.M., Li Puma, G. (2015) Novel microfluidics approach for extremely fast and efficient photochemical transformations in fluoropolymer microcapillary films. ChemicalCommunications $51,8414-8417$.

Richardson, S.D. (2012) Environmental mass spectrometry: emerging contaminants and current issues. Analytical Chemistry 84, 747-778. 
647 Richardson, S.D., Plewa, M.J.,Wagner, E.D., Schoeny, R., DeMarini, D.M. (2007) Occurrence, 648 genotoxicity, and carcinogenicity of regulated and emerging disinfection by-products in drinking 649 water: a review and roadmap for research. Mutation Research 636(1-3), 178-242.

650 Rozas, O., Vidal, C., Baeza, C., Jardim, W.F., Rossner, A., Mansilla, H.D. (2016) Organic 651 micropollutants (OMPs) in natural waters: Oxidation by $\mathrm{UV} / \mathrm{H}_{2} \mathrm{O}_{2}$ treatment and toxicity 652 assessment. Water Research 98, 109-118.

653 Russo, D., Spasiano, D., Vaccaro, M., Andreozzi, R., Li Puma, G., Reis, N.M., Marotta, R. (2016) 654 Direct photolysis of benzoylecgonine under UV irradiation at $254 \mathrm{~nm}$ in a continuous flow 655 microcapillary array photoreactor. Chemical Engineering Journal 283, 243-250.

656 Sanderson, H., Johnson, D.J., Reitsma, T., Brain, R.A., Wilson, C.J., Solomon, K.R. (2004) 657 Ranking and prioritization of environmental risks of pharmaceuticals in surface waters. Regulatory 658 Toxicology and Pharmacology 39(2), 158-183.

659 Shi, P., Jia, S., Zhang, X.X., Zhang, T., Cheng, S., Li, A. (2013) Metagenomic insights into 660 chlorination effects on microbial antibiotic resistance in drinking water. Water Research 47, 111661120.

662 Singer, A.C., Nunn, M.A., Gould, E.A., Johnson, A.C. (2007) Potential risks associated with the 663 proposed widespread use of Tamiflu. Environmental Health Perspectives 115(1), 102-106.

664 Sinha, V.R., Monika, Trehan, A., Kumar, M., Singh, S., Bhinge, J.R. (2007) Stress studies on 665 Acyclovir. Journal of Chromatographic Science 45, 319-324.

666 Spasiano, D., Russo, D., Vaccaro, M., Siciliano, A., Marotta, R., Guida, M., Reis, N.M., Li Puma, 667 G., Andreozzi, R. (2016) Removal of benzoylecgonine from water matrices through $\mathrm{UV}_{254} / \mathrm{H}_{2} \mathrm{O}_{2}$ 668 process: reaction kinetic modeling, ecotoxicity and genotoxicity assessment. Journal of Hazardous 669 Materials 318, 515-525.

670 Yuan, F., Hu, C., Hu, X., Wei, D., Chen, Y., Qu, J. (2011) Photodegradation and toxicity changes 671 of antibiotics in UV and $\mathrm{UV} / \mathrm{H}_{2} \mathrm{O}_{2}$ process. Journal of Hazardous Materials 185, 1256-1263. 
672 Zhou, C., Chen, J., Xie, Q., Wei, X., Zhang, Y., Fu, Z. (2015) Photolysis of three antiviral drugs

673 acyclovir, zidovudine and lamivudine in surface freshwater and seawater. Chemosphere 138, 792674797. 


\begin{tabular}{|c|c|c|c|}
\hline $\begin{array}{c}\text { WWTP effluent } \\
(\mathrm{ng} / \mathrm{L})\end{array}$ & $\begin{array}{c}\text { Surface water } \\
(\mathrm{ng} / \mathrm{L})\end{array}$ & Location & Ref \\
\hline $27.3-53.3$ & $2.2-190$ & Germany & (Prasse et al., 2010) \\
\hline $121-148$ & $5-25$ & Germany & (Prasse et al., 2011) \\
\hline $44.0-650$ & -- & Germany & (Funke et al., 2016) \\
\hline $114-205$ & $8.9-112.6$ & China & (Peng et al., 2014) \\
\hline $12-50$ & $10-23$ & Japan & (Azuma et al., 2016) \\
\hline 947 & $738-1590$ & USA & (Bradley et al., 2014) \\
\hline 154 & -- & USA & (McCurry et al., 2014) \\
\hline
\end{tabular}

Table 1 


\begin{tabular}{|c|c|c|c|}
\hline 3) & $\mathrm{ACY} \stackrel{h v}{\rightarrow} \mathrm{TPs}$ & $\emptyset_{A C Y}$ & $\begin{array}{l}\text { (estimated in this } \\
\text { study) }\end{array}$ \\
\hline 4) & $\mathrm{H}_{2} \mathrm{O}_{2} \stackrel{h v}{\rightarrow} 2 \mathrm{HO}^{\bullet}$ & $\begin{array}{l}\emptyset_{\mathrm{H}_{2} \mathrm{O}_{2}}=0.55 \mathrm{~mol} \cdot \mathrm{ein}^{-1} \\
\varepsilon_{254}^{\mathrm{H}_{2} \mathrm{O}_{2}}=18.6 \mathrm{M}^{-1} \cdot \mathrm{cm}^{-1}\end{array}$ & (Goldstein et al., 2007) \\
\hline 5) & $\mathrm{HO}^{\bullet}+\mathrm{H}_{2} \mathrm{O}_{2} \stackrel{k_{h}}{\longrightarrow} \mathrm{H}_{2} \mathrm{O}+\mathrm{HO}_{2}^{\bullet}$ & $k_{h}=2.7 \cdot 10^{7} M^{-1} \cdot s^{-1}$ & (Buxton et al., 1988) \\
\hline 6) & $\mathrm{ACY}+\mathrm{HO}^{\bullet} \stackrel{k_{O H} / A C Y}{\longrightarrow} \mathrm{TPs}$ & $k_{O H / A C Y}$ & $\begin{array}{l}\text { (estimated in this } \\
\text { study) }\end{array}$ \\
\hline 7) & $\mathrm{TPs}+\mathrm{HO} \cdot \stackrel{k_{O H / T P}}{\longrightarrow} \mathrm{TP}$ & $k_{O H / T P}$ & $\begin{array}{l}\text { (estimated in this } \\
\text { study) }\end{array}$ \\
\hline 8) & $2 \mathrm{HO}_{2}^{\cdot} \stackrel{k_{t}}{\longrightarrow} \mathrm{H}_{2} \mathrm{O}_{2}+\mathrm{O}_{2}$ & $k_{t}=8.3 \cdot 10^{5} M^{-1} \cdot s^{-1}$ & (Bielski et al., 1985) \\
\hline 9) & $\frac{d\left[\mathrm{HO}^{\bullet}\right]}{d \tau}=2 \mathrm{~F}_{\mathrm{H}_{2} \mathrm{O}_{2}}-\left[\mathrm{HO} \mathrm{O}^{\bullet}\right] \cdot\left(k_{h} \cdot[\right.$ & $\left.k_{O H / A C Y} \cdot[A C Y]-k_{O H / T P} \cdot[T P s]\right)$ & \\
\hline 10) & $F_{\mathrm{H}_{2} \mathrm{O}_{2}}=\emptyset_{\mathrm{H}_{2} \mathrm{O}_{2}} \cdot P_{o} \cdot(1-\exp (-2.3 \cdot$ & $\left.\left.\left.A C Y=[A C Y]+\varepsilon_{254}^{H_{2} O_{2}} \cdot\left[H_{2} O_{2}\right]\right)\right)\right) \cdot f_{H_{2} O_{2}}$ & \\
\hline 11) & $\frac{d\left[\mathrm{HO}_{2}^{\circ}\right]}{d \tau}=k_{h} \cdot[H$ & $\left.\mathrm{O}_{2}\right]-2 k_{t} \cdot\left[\mathrm{HO}_{2}^{*}\right]^{2}$ & \\
\hline 12) & $\frac{d[A C Y]}{d \tau}=-F_{A C Y}$ & ${ }_{A C Y} \cdot[A C Y] \cdot\left[H O^{\bullet}\right]$ & \\
\hline 13) & $F_{A C Y}=\emptyset_{A C Y} \cdot P_{o} \cdot(1-\exp (-2.3 \cdot$ & $\left.\left.\left.=254 \cdot[A C Y]+\varepsilon_{254}^{\mathrm{H}_{2} \mathrm{O}_{2}} \cdot\left[\mathrm{H}_{2} \mathrm{O}_{2}\right]\right)\right)\right) \cdot f_{A C Y}$ & \\
\hline
\end{tabular}

Table 2 


\begin{tabular}{|c|c|c|}
\hline \multicolumn{3}{|c|}{$\mathbf{U V}_{254}$} \\
\hline Sample & $\begin{array}{l}\text { First brood } \\
\text { (day) }\end{array}$ & $\begin{array}{l}\text { Number of Living } \\
\text { offspring } \\
\text { per parent animal }\end{array}$ \\
\hline Control solution & 8 & $78 \pm 5$ \\
\hline $\mathrm{UV}_{254}$ dose: $0 \mathrm{~mJ} \cdot \mathrm{cm}^{-2}$ & 10 & $72 \pm 3$ \\
\hline $\begin{array}{l}\mathrm{UV}_{254} \text { dose: } 864 \mathrm{~mJ} \cdot \mathrm{cm}^{-2} \\
\text { TOC removal degree: }<\mathbf{5 \%}\end{array}$ & 15 & $42 \pm 3$ \\
\hline $\begin{array}{l}\mathrm{UV}_{254} \text { dose: } 2356 \mathrm{~mJ} \cdot \mathrm{cm}^{-2} \\
\text { TOC removal degree: }<5 \%\end{array}$ & 17 & $37 \pm 6$ \\
\hline $\begin{array}{l}\mathrm{UV}_{254} \text { dose: } 4712 \mathrm{~mJ} \cdot \mathrm{cm}^{-2} \\
\text { TOC removal degree: } \sim \mathbf{5 \%}\end{array}$ & 11 & $68 \pm 5$ \\
\hline \multicolumn{3}{|c|}{$\mathrm{UV}_{254} / \mathrm{H}_{2} \mathrm{O}_{2}$} \\
\hline Sample & $\begin{array}{l}\text { First brood } \\
\text { (day) }\end{array}$ & $\begin{array}{l}\text { Number of Living } \\
\text { offspring } \\
\text { per parent animal }\end{array}$ \\
\hline Control solution & 8 & $75 \pm 1$ \\
\hline $\mathrm{UV}_{254}$ dose: $0 \mathrm{~mJ} \cdot \mathrm{cm}^{-2}$ & 10 & $74 \pm 4$ \\
\hline $\begin{array}{l}\mathrm{UV}_{254} \text { dose: } 280 \mathrm{~mJ} \cdot \mathrm{cm}^{-2} \\
\text { TOC removal degree: } 28 \%\end{array}$ & 9 & $69 \pm 5$ \\
\hline $\begin{array}{l}\mathrm{UV}_{254} \text { dose: } 950 \mathrm{~mJ} \cdot \mathrm{cm}^{-2} \\
\text { TOC removal degree: } 77 \%\end{array}$ & 9 & $65 \pm 2$ \\
\hline $\begin{array}{l}\mathrm{UV}_{254} \text { dose: } 1900 \mathrm{~mJ} \cdot \mathrm{cm}^{-2} \\
\text { TOC removal degree: > } 95 \%\end{array}$ & 9 & $70 \pm 2$ \\
\hline
\end{tabular}

Table 3 
$\mathbf{U V}_{254}$

\begin{tabular}{|c|c|c|c|}
\hline $\mathbf{n}^{\circ}$ & Previously reported & Measured mass $[\mathrm{M}+\mathrm{H}]^{+}(\mathrm{Da})$ & Structure $^{\left({ }^{\circ}\right)}$ \\
\hline $\mathbf{I}$ & NO & 136.93 & \\
\hline II & YES, An et al, 2015 & 158.15 & \\
\hline III & NO & 202.18 & \\
\hline IV & YES, An et al, 2015 & 242.98 & \\
\hline $\mathbf{V}$ & YES, An et al, 2015 & 258.98 & \\
\hline
\end{tabular}

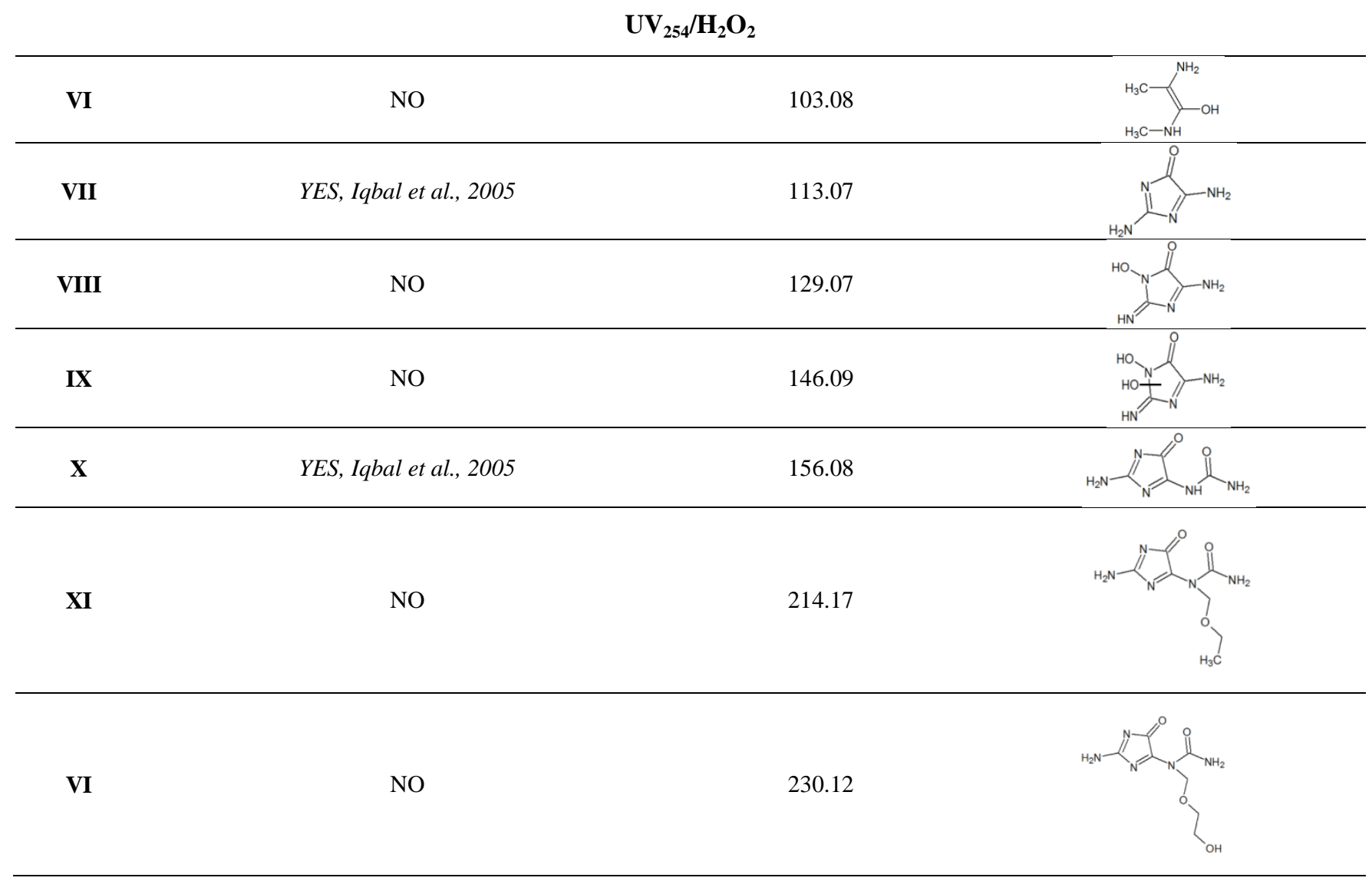

Table 4 

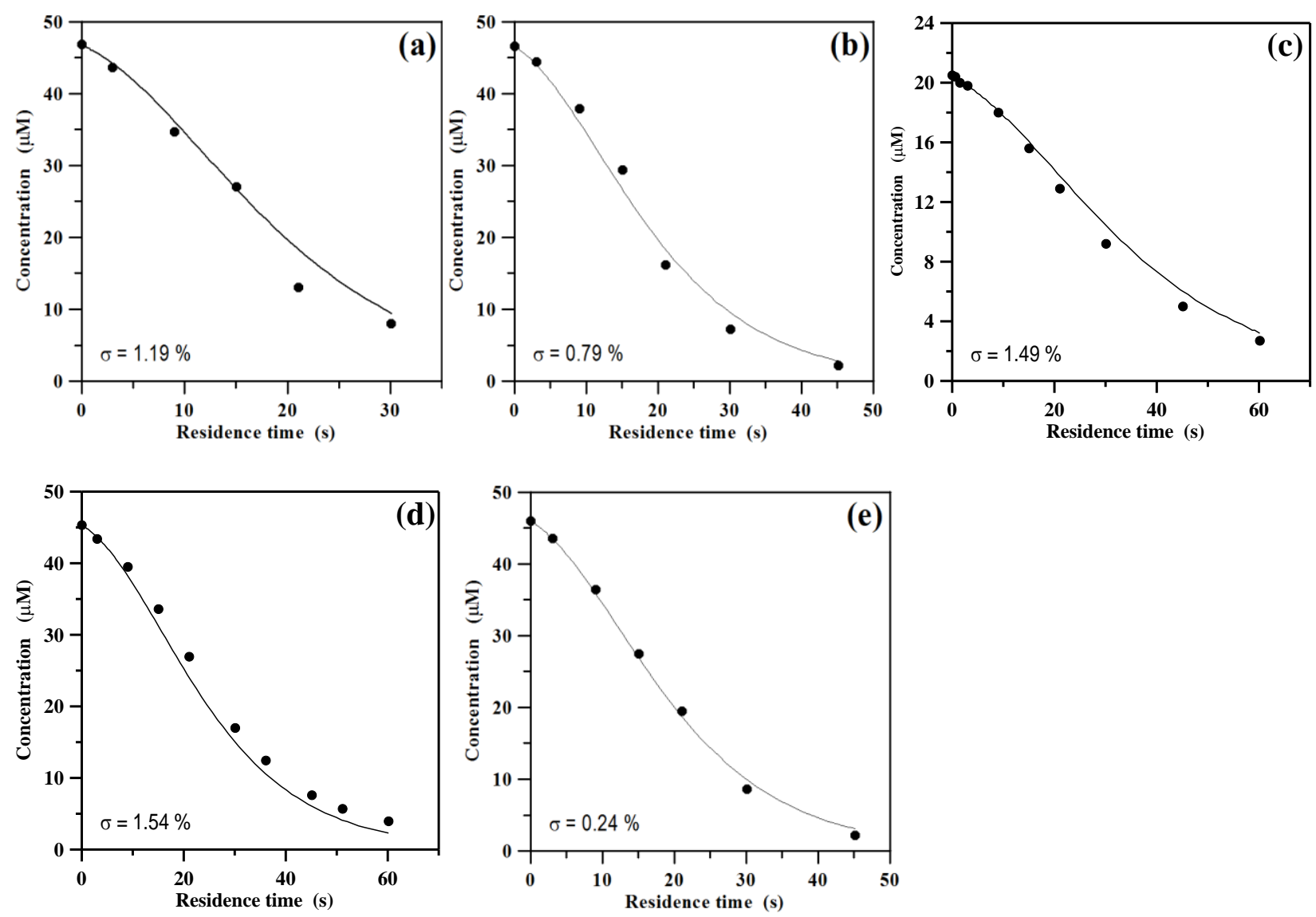

Figure 1 

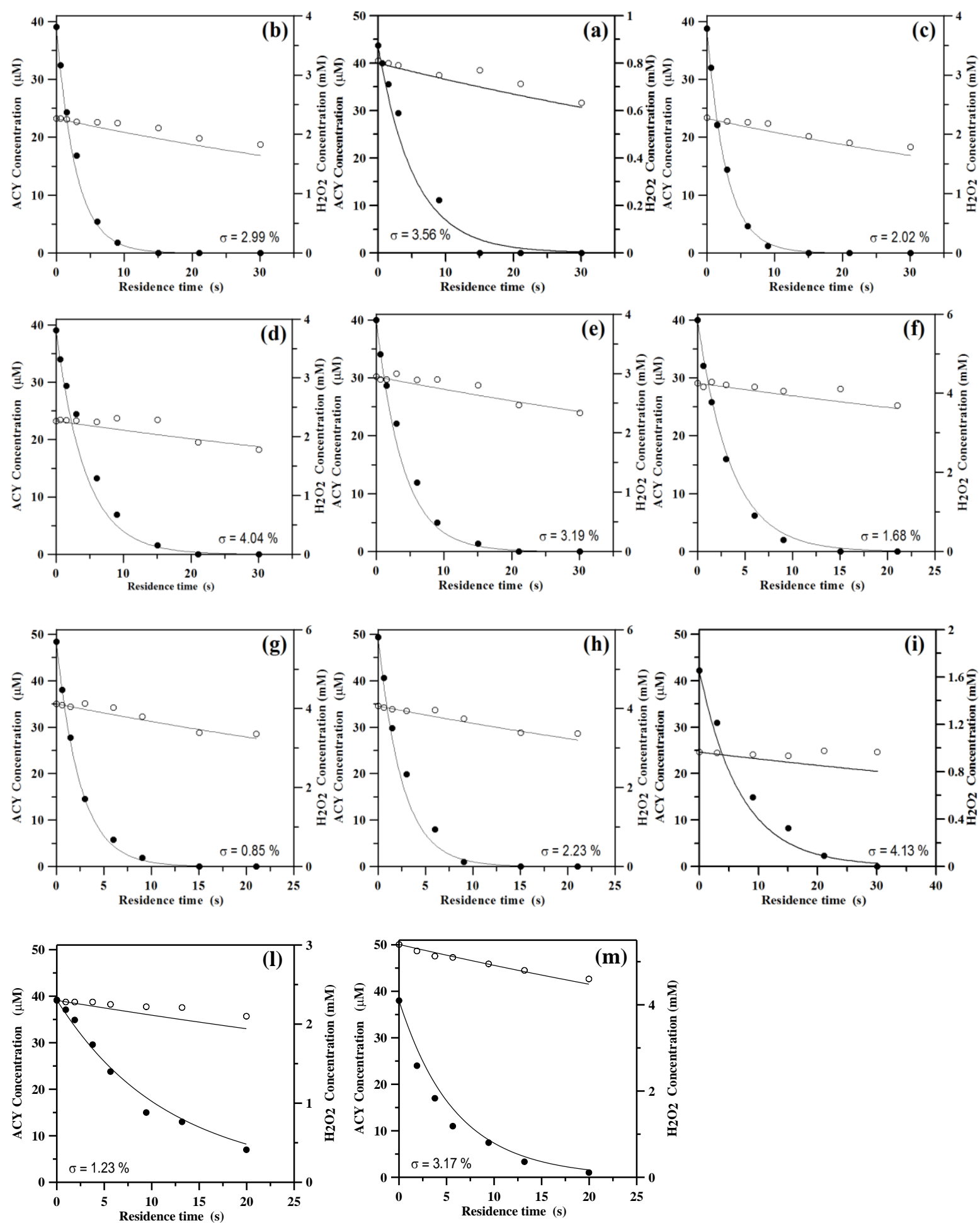

Figure 2 

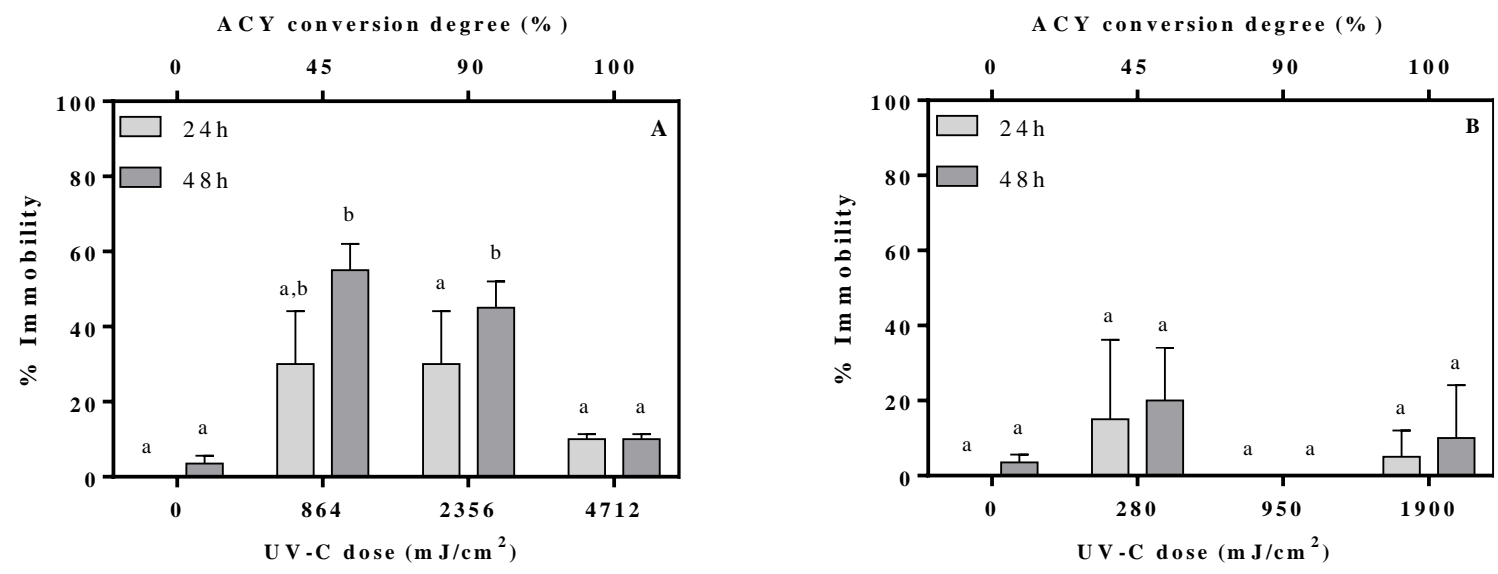

Figure 3 


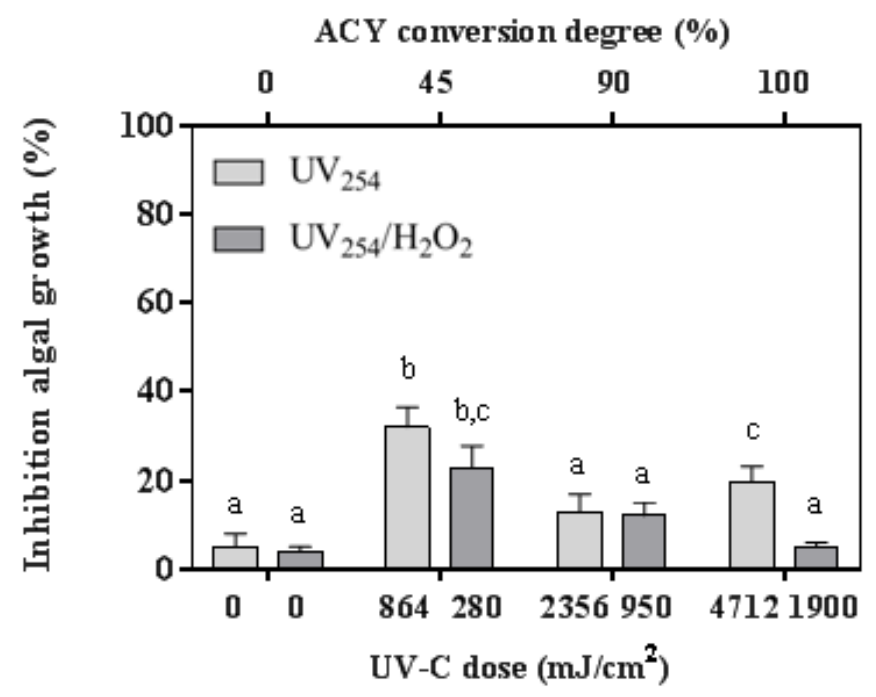

Figure 4 

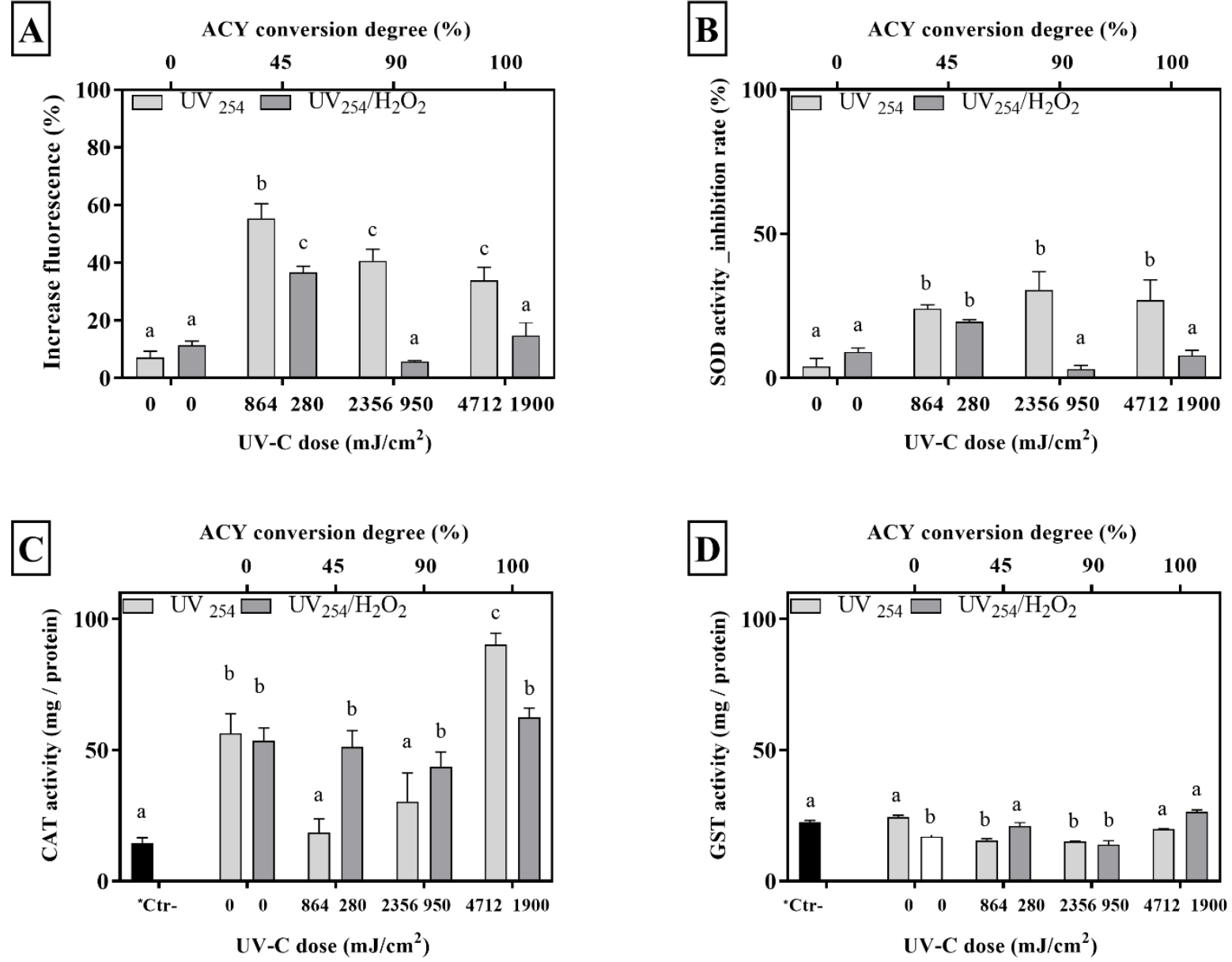

Figure 5 

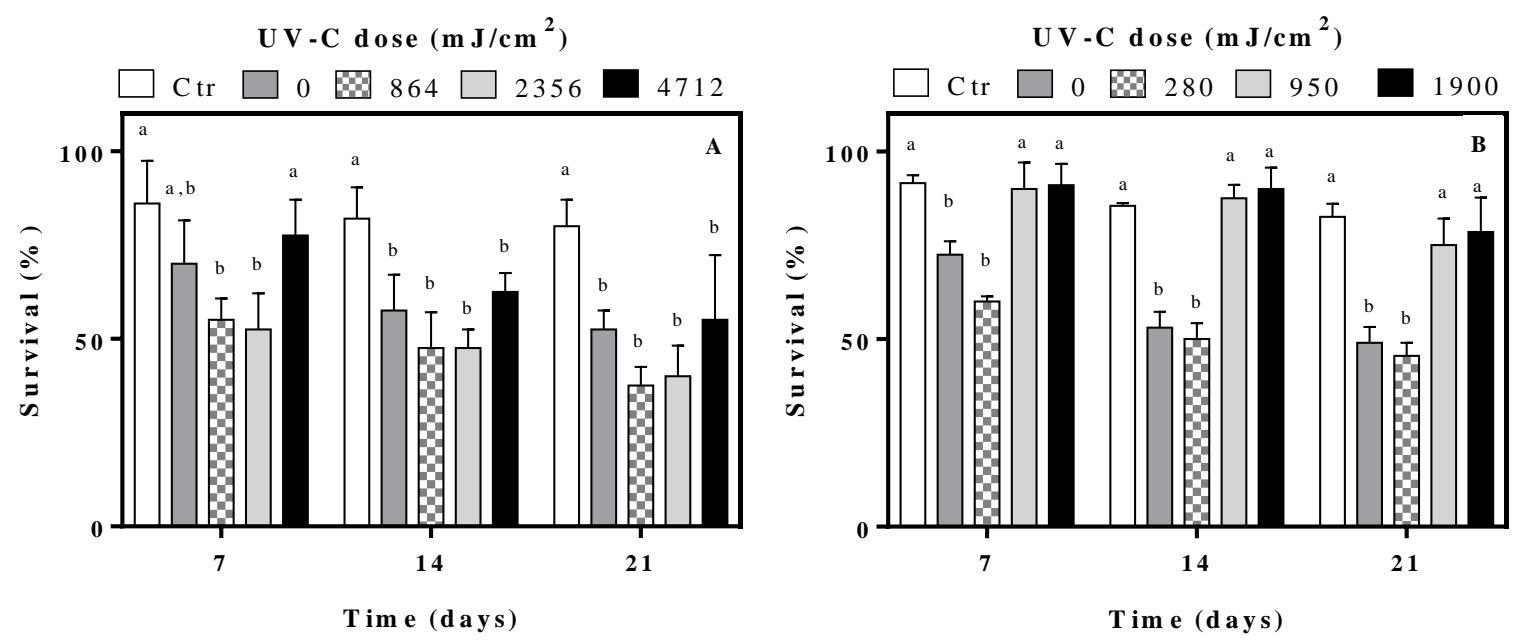

Figure 6 
Figure 1: Comparison between experimental (circle) and predicted (line) data for $\mathrm{UV}_{254}$ photolysis of ACY at different $\mathrm{pH}$ and power of lamp in the MCF photoreactor.

(a) $\mathrm{pH}=6.0(8.0 \mathrm{~W})$; (b) $\mathrm{pH}=4.0(8.0 \mathrm{~W})$; (c,d) $\mathrm{pH}=6.0(4.5 \mathrm{~W})$; (e) $\mathrm{pH}=8.5(8.0 \mathrm{~W})$.

Figure 2: Comparison between experimental (circle) and predicted (line) data for $\mathrm{UV}_{254} / \mathrm{H}_{2} \mathrm{O}_{2}$ photodegradation of ACY $(\bullet)$ and hydrogen peroxide $(O)$ in the MCF photoreactor at different $\mathrm{pH}$, power of lamp and starting $\mathrm{H}_{2} \mathrm{O}_{2}$ load. Optimization mode (a-f), simulation mode (g-m).

(a): $\mathrm{pH}=6.0\left(8.0 \mathrm{~W},\left[\mathrm{H}_{2} \mathrm{O}_{2}\right]_{\mathrm{o}} /[\mathrm{ACY}]_{\mathrm{o}}=20\right) ;(\mathbf{b}): \mathrm{pH}=6.0\left(8.0 \mathrm{~W},\left[\mathrm{H}_{2} \mathrm{O}_{2}\right]_{\mathrm{o}} /[\mathrm{ACY}]_{\mathrm{o}}=50\right)$;

(c): $\mathrm{pH}=8.0\left(8.0 \mathrm{~W},\left[\mathrm{H}_{2} \mathrm{O}_{2}\right]_{\mathrm{o}} /[\mathrm{ACY}]_{\mathrm{o}}=50\right) ;(\mathbf{d}): \mathrm{pH}=6.0\left(4.5 \mathrm{~W},\left[\mathrm{H}_{2} \mathrm{O}_{2}\right]_{\mathrm{o}} /[\mathrm{ACY}]_{\mathrm{o}}=50\right)$;

(e): $\mathrm{pH}=6.0\left(4.5 \mathrm{~W},\left[\mathrm{H}_{2} \mathrm{O}_{2}\right]_{\mathrm{o}} /[\mathrm{ACY}]_{\mathrm{o}}=70\right) ;(\mathbf{f}): \mathrm{pH}=6.0\left(4.5 \mathrm{~W},\left[\mathrm{H}_{2} \mathrm{O}_{2}\right]_{\mathrm{o}} /[\mathrm{ACY}]_{\mathrm{o}}=100\right)$;

(g): $\mathrm{pH}=4.0\left(8.0 \mathrm{~W},\left[\mathrm{H}_{2} \mathrm{O}_{2}\right]_{\mathrm{o}} /[\mathrm{ACY}]_{\mathrm{o}}=100\right) ;(\mathbf{h}): \mathrm{pH}=8.2\left(8.0 \mathrm{~W},\left[\mathrm{H}_{2} \mathrm{O}_{2}\right]_{\mathrm{o}} /[\mathrm{ACY}]_{\mathrm{o}}=100\right)$;

(i): $\mathrm{pH}=4.0\left(4.5 \mathrm{~W},\left[\mathrm{H}_{2} \mathrm{O}_{2}\right]_{\mathrm{o}} /[\mathrm{ACY}]_{\mathrm{o}}=20\right)$; (l) $\mathbf{p H}=\mathbf{6 . 0}\left(\mathbf{8 . 0} \mathrm{W},\left[\mathrm{H}_{2} \mathrm{O}_{2}\right]_{\mathrm{o}} /[\mathrm{ACY}]_{\mathrm{o}}=\mathbf{6 0}\right)$;

(m) $\mathrm{pH}=6.0\left(8.0 \mathrm{~W},\left[\mathrm{H}_{2} \mathrm{O}_{2}\right]_{0} /[\mathrm{ACY}]_{0}=142\right)$.

Figure 3: Evolution of acute toxicity with D. magna (24 h and $48 \mathrm{~h})$ during the $\mathrm{UV}_{254}(\mathbf{A})$ and $\mathrm{UV}_{254} / \mathrm{H}_{2} \mathrm{O}_{2}$ (B) treatments. Data with different letters (a-b) are significantly different (Tukey's, $\mathrm{p}<0.05)$

Figure 4: Toxicity data with $R$. subcapitata $(72 \mathrm{~h})$. Data with different letters $(\mathrm{a}-\mathrm{c})$ are significantly different (Tukey's, $\mathrm{p}<0.05$ ).

Figure 5: Effects of $\mathrm{UV}_{254}$ and $\mathrm{UV}_{254} / \mathrm{H}_{2} \mathrm{O}_{2}$ processes on (A) ROS production, (B) SOD, (C) Cat, (D) GST in Daphnia magna after $48 \mathrm{~h}$ of exposure. For each parameter, mean and standard deviation are shown. Data with different letters (a-d) are significantly different (Tukey's, $p<0.05$ ). *Ctr- (negative control) 
Figure 6: Survival curves of D. magna during the time of exposure (21 days) for $\mathrm{UV}_{254}$ (A) and $\mathrm{UV}_{254} / \mathrm{H}_{2} \mathrm{O}_{2}$ (B) treated solutions. Data with different letters (a-b) are significantly different (Tukey's, $\mathrm{p}<0.05)$. Dilution: 1:100.

Table 1: Occurrence of ACY in WWTP effluents and in surface waters.

Table 2: Reaction kinetics mechanism of ACY photoxidation by $\mathrm{UV}_{254} / \mathrm{H}_{2} \mathrm{O}_{2}$ process and mass balance equations. The terms $f_{\mathrm{H}_{2} \mathrm{O}_{2}}$ and $f_{A C Y}$ indicate the fraction of $\mathrm{UV}_{254}$ radiation absorbed by hydrogen peroxide and ACY respectively. The TPs concentration was assumed equal to the amount of ACY consumed ([ACY $\left.]_{0}-[\mathrm{ACY}]\right)$.

$\varepsilon_{254}^{\mathrm{H} 2 \mathrm{O} 2}$ and $\phi_{\mathrm{H} 2 \mathrm{O} 2}$ are the molar absorption coefficient and the quantum yield of photolysis of for hydrogen peroxide at $254 \mathrm{~nm}$ respectively.

Table 3: First brood and live offspring after 21 days of $D$. magna exposure for different $\mathrm{UV}_{254}$ doses (with and without hydrogen peroxide).

Table 4: Molecular structures of the chemical species identified from the MS spectra of samples submitted to $\mathrm{UV}_{254}$ and $\mathrm{UV}_{254} / \mathrm{H}_{2} \mathrm{O}_{2}$ photolysis.

$\left.{ }^{(}\right)$The structures proposed on the basis of the pseudo-molecular $[\mathrm{M}+\mathrm{H}]^{+}$ion due to the low intensity of the MS/MS fragmentation signals. 